\title{
Reconstruction of the Grenfell Tower Fire-Thermomechanical Analysis of Window Failure During the Grenfell Tower Disaster
}

\author{
Maxime Koohkan, Virginie Dréan, Bertrand Girardin*, Eric Guillaume and \\ Xavier Duponchel, Efectis France, route de l'Orme Des Merisiers, 91193 Saint \\ Aubin Cedex, France \\ Talal Fateh, Efectis UK-Ireland, Jordanstown Campus Block 27, Shore Road, \\ Newtownabbey BT37 OQB, UK and Ulster University, FIRESERT, \\ Jordanstown Campus Block 27, Shore Road, Newtownabbey BT37 OQB, \\ $U K$
}

Received: 14 June 2019/Accepted: 4 April 2020

\begin{abstract}
Observations and numerical studies have allowed an understanding the fire development inside apartments and over the façade during the Grenfell Tower fire. During these analyses, the highlighted need was for a deeper investigation into the failure of windows during the fire. This detailed and complex model for window failure validates the thermal breakage criteria used in fire simulations of the whole Grenfell Tower fire. However, the present investigation is dedicated to a single pathway for the influx of fire and toxic smoke. Other pathways from the façade to the apartments, such as the melting of elements surrounding the window frame, are not addressed here. To analyse window behaviour during fire, Finite Element Method thermomechanical modelling is used. First, a heat transfer analysis is performed for windows subjected to the external flames from the identified façade fire scenario. The thermal loads evaluated from the fire are applied to the window structures to estimate their failure times. Two window casement configurations, closed and tilted-in, are investigated numerically. Then, a thermomechanical analysis of the window is addressed for each casement configuration. The modelled failure times are compared with those used in the general fire development model and from the observations. The good correlation that is observed, regardless of casement configuration, justifies the use of a simplified criterion for window failure in CFD fire models.
\end{abstract}

Keywords: Heat transfer analysis, Thermal actions, Fire development model, Thermomechanical behaviour, Window failure

\footnotetext{
*Correspondence should be addressed to: Eric Guillaume, E-mail: eric.guillaume@efectis.com
} 


\section{Introduction}

The fire behaviour of windows installed in a building façade has an important influence on fire development during an enclosure fire. When subjected to the thermal actions of a fire, windows may have little fire resistance and thus can fail. When failed, windows transform into additional ventilation openings, which modify the supply of fresh air into the enclosure. With regard to the building envelope, the ventilation inlets created from windows will be one of the decisive factors in a fire scenario involving small enclosures, typical of dwellings [1, 2]. Furthermore, openings in a façade can cause fire re-entry into further enclosures, and lead to further fire propagation when the contents of that enclosure ignite [3-5].

It is therefore essential to evaluate the conditions that cause the failure of windows for a given fire scenario and enclosure configuration. Several different phenomenon cause glass to break under thermal loads. However, they can be categorized as follows [6]:

- thermal shock due to the thermal gradient created across the thickness of the glass when high heat flux is imparted suddenly on one side of a pane;

- thermal gradient over the thickness of the glass causes deformation, in particular at the corners of the pane;

- non-uniform heating when parts of the pane are shaded from radiation, for example, where the edge of a pane is shaded by the frame (Thermal expansion places the cooler portion in tension. This results in stress between the centre of the pane and the shaded area as the temperature difference increases.);

- mechanical stress due to heat-related deformation of the frame when submitted to temperature loading; and

- mechanical loss of mounting and fixing of pre-frames, if in use.

In recent years, a number of studies, both theoretical and experimental, have addressed the performance of ordinary windows exposed to fire or heat flows. Several studies have proposed temperature difference as a parameter to assess glass breakage [6-9]. Others have attempted to establish a criterion for the prediction of glass fallout for single glazing, and both criteria are discussed in [10]. Engineering correlations based on experimental results for single glazing are given in reference [11], establishing relations between window failure and data such gas temperature, incident heat flux, or rate of heat release. A more extensive approach is provided in [12] based on a predetermined amount of successive cracks. Other studies have attempted to assess the fallout of multi-pane glazing when subjected to fire [13-18]. Experimental research [17] indicated that double-glazing, although considerably weakened, remained intact for a relatively long time. Information collected during these experimental studies helped to highlight the mechanism of glass failure. Under the effect of a non-uniform temperature distribution in the pane, and the thermal stresses that result, the glass cracks and then breaks completely once the cracking has become excessive. Numerical models have also been used to predict the first fracture of glass [19-22] and glass fallout [23]. The finite element method provided in $[24,25]$ gives a comprehensive method to assess glass 
breakage in relation to the first crack, based on spectral discrete ordinates radiation models and taking into account the spectral sensitivity of the glass in the infrared spectrum and mechanical stresses. The use of a field model like the CFD code FDS to predict glass breakage has also been studied [26, 27]. Thermomechanical analyses are addressed in $[15,28]$. In particular, the failure mechanism for the formation of a ventilation opening from a glazed element comprising a window frame with thermal break is investigated in reference [15]. After analysing the data collected and observations made during tests, it appeared that a single crack is not sufficient to cause the complete fallout of the glazing.

The deformation of window frames seemed to have little influence on the mechanism of glazing cracking, at least with regard to the appearance of the first cracks, and the fire-rated windows may form a ventilation opening because of the failure of the frame, which may occur before the failure of the glazing. The failure time of an aluminium frame is defined in [15] as the time at which the polymeric thermal breaks in the frame reach their melting temperature. The time of occurrence of the first crack does not correspond to the appearance of a ventilation opening (total destruction of the glazing) and the progression of cracking, unlike its initiation, has been neglected in most models. Indeed, for the sake of simplification, it has been accepted that glazing, when exposed to fire, fails and forms a ventilation opening at the time the first crack forms.

However, few numerical models take into account both the impact of an external fire and the full detail of the window frame, which would lead to simulations with a high level of complexity.

The Grenfell Tower is a 24 storey high-rise building, refurbished in the period 2012-2016 with a new insulated ventilated façade system, installed on all of the building's elevations, and new windows. The new windows were not fire-rated. The Grenfell Tower fire happened on June, 14th 2017 and caused more than 70 deaths [29]. The fire spread to the façade from a fire in an apartment resulting in external flames. The initial fire, before spreading outside, was localised in the kitchen of Flat 16, on the 4th floor of the East façade of the Tower. This has been extensively detailed in expert reports and is shown in video and photographic records of the real fire [30-32]. These records were also used to provide an analysis of the post-break-out vertical and horizontal fire propagation over the whole façade of the tower in [33].

Along with the combustible cladding mounted on the façade, the windows appear to have facilitated the spread of fire between the interior and exterior of the building. Furthermore, the deformation and fallout of the windows and surrounding elements seems to be one of the main reasons for the spread of the fire to the cladding during the early stages of the fire. Later, when the fire was fully developed, the heat fluxes imparted to the windows were high enough to break the window panes whatever the surrounding materials (Chapter 24 of [29]). As concluded by Professor Bisby in [29], the most likely route of flame spread, from the initial apartment to those above, was via the side of the window and into the column cavity following deformation of the UPVC (unplasticized polyvinyl chloride) window surrounds, and that after that the window frame was partially failed. However, window failure was probably not the only way of flame exit and re-en- 
try, and it is probable that there were multiple failure modes from window or its surrounds during the Grenfell fire, as summarized in Table 1. The scenario leading to one of the earliest massive inflows of fire effluents appears to be the deformation of the window frame and it is thus investigated in the present work.

Reference [34] investigated the development of the initial internal kitchen fire at Grenfell Tower, its propagation through and around the kitchen window opening, over the façade, and its re-entry into subsequent compartments. Three dimensional (3D) numerical simulations were performed with the Computational Fluid Dynamics (CFD) code Fire Dynamics Simulator (FDS) [35]. It included validation by comparison with video and photographic observations of the real fire. Thermal loads on window frames, from the apartment and façade fires, were evaluated numerically. The predicted time to first thermal failure of the windows was around 4-5 min. In [36] numerical simulations were addressed to investigate the fire spread over the façade and its re-entry into the tower. Thermal criteria from the CFD model of [34] were used for window failure during the vertical spread of the fire. These simulations illustrated the influence of the fire performance of the windows by modelling fire spread over the Tower façade without any thermal failure of the windows.

In the present study, ANSYS Mechanical APDL software [37] is used to perform a thermomechanical analysis of a window frame, as used in the Grenfell Tower refurbishment, to evaluate the heating of the different materials comprising the frame. A full three-dimensional (3D) mechanical finite element model is then built to evaluate the failure mode of the window. The thermal loads derived from modelling [34] of the external façade fire are applied as boundary conditions on the frame.

\section{Table 1}

\section{Synthesis of the main failure modes of a window during fire development, and their resulting consequences}

\begin{tabular}{|c|c|c|c|}
\hline Failure mode & Main consequences & $\begin{array}{l}\text { Resulting } \\
\text { inlet }\end{array}$ & $\begin{array}{l}\text { Fire develop- } \\
\text { ment }\end{array}$ \\
\hline $\begin{array}{l}\text { Thermal shock on one side of a glass } \\
\text { pane }\end{array}$ & $\begin{array}{l}\text { Local glass breakage-first } \\
\text { pane in case of double glaz- } \\
\text { ing }\end{array}$ & Reduced & EARLY \\
\hline $\begin{array}{l}\text { Mechanical losses of mounting and fixing } \\
\text { such PVC reveal liner }\end{array}$ & $\begin{array}{l}\text { Pathway surrounding the } \\
\text { window }\end{array}$ & $\begin{array}{l}\text { Local at } \\
\text { surround }\end{array}$ & \\
\hline $\begin{array}{l}\text { Mechanical stress due to deformation of } \\
\text { the frame and its aluminium profiles }\end{array}$ & $\begin{array}{l}\text { Failure of the whole glass } \\
\text { pane }\end{array}$ & Massive & \\
\hline $\begin{array}{l}\text { Thermal gradient at the shaded corners of } \\
\text { the glass pane }\end{array}$ & $\begin{array}{l}\text { Local glass breakage-first } \\
\text { pane in case of double glaz- } \\
\text { ing }\end{array}$ & $\begin{array}{l}\text { Local } \\
\text { then mas- } \\
\text { sive }\end{array}$ & LATE \\
\hline $\begin{array}{l}\text { Failure of aluminium supporting pre- } \\
\text { frame rails }\end{array}$ & Failure of the whole window & Massive & $\begin{array}{l}\text { Protected by } \\
\text { PIR insulant }\end{array}$ \\
\hline
\end{tabular}


The aim of the current study is to perform a deeper investigation into the thermal and thermo-mechanical behaviour, during the disaster, of the window system installed on Grenfell Tower, along with an evaluation of the thermal criteria for window failure. The influence of the initial opening position of the window casements is also investigated to enhance the understanding of the several failure modes (inward or outward fallout) of the window frames observed after the fire event. The relationship between the initial position of the casements during the fire (closed, tilted-in) and the window's fallout mode can then be interrogated, as well as the time to failure depending on a given casement opening configuration. Furthermore, the resultant detailed and complex model allows the evaluation of the relevance of the hypothesis used in previous numerical studies of the Grenfell fire $[34,37]$.

\section{Description of the Window Structure}

\subsection{Window Structure}

During the refurbishment of the Tower, the windows frames have been installed in line with the pre-existing openings in the reinforced concrete building envelope [30-32], and mounted on continuous aluminium rails which were mechanically fixed into the existing concrete structure at the top and bottom of the window openings. After the refurbishment, the new windows were offset by approximately $180 \mathrm{~mm}$ towards the outside of the building compared with the existing windows. For each window, uPVC reveal linings have been installed between the frame and the concrete structure in order to fill the gap between the new and old window location.

The window combinations used in the refurbishment of Grenfell Tower varied according to location on the Tower. However, the type of window construction is similar across the entire building on or above the 4th floor (Fig. 1). The current study focuses on the "Thermally Broken Tilt and Turn Window System 5-20" window frame, sized $1241 \mathrm{~mm} \times 1285 \mathrm{~mm}$ [38], comprising $26 \mathrm{~mm}$ thick doubleglazed units. The glazing is set inside a two-component (double-wall) aluminium frame structure, with the two extruded aluminium profiles connected by a polyamide thermal break (Fig. 1b). Window assemblies comprise this powder-coated aluminium framing and fixed and openable double-glazed window units with various sizes and opening configurations (inward swinging or inward tilting). In some locations, in particular in kitchens, extract fan units were fitted within aluminium faced, extruded polystyrene foam filled, composite window infill panels. 


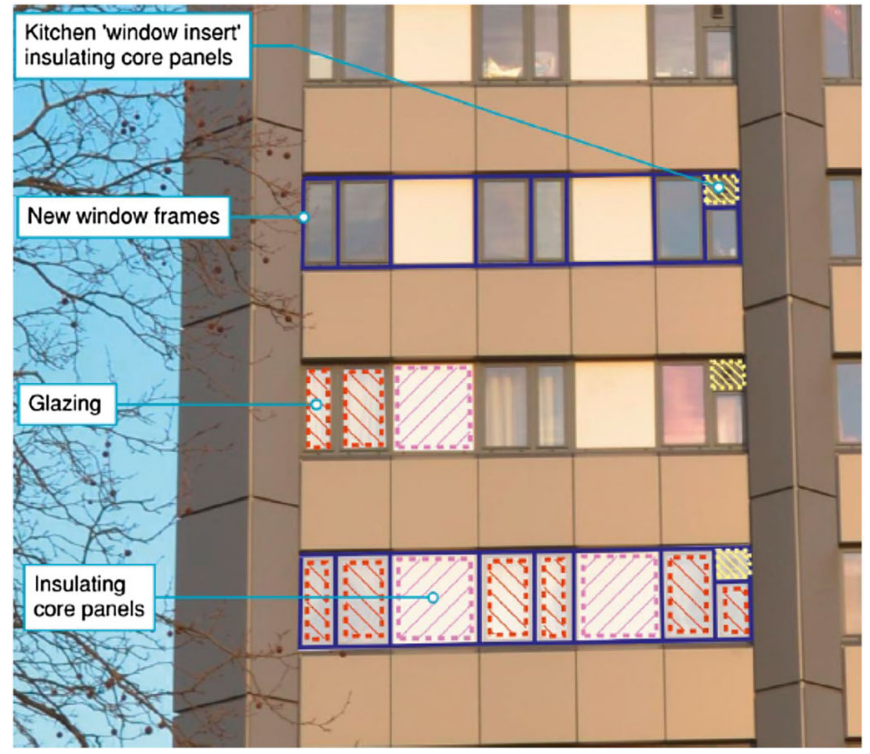

(a)

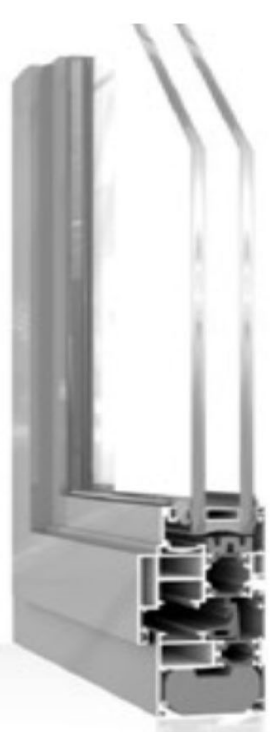

(b)

Figure 1. a View and schematics of the different window framing arrangements used for different parts of Grenfell Tower at or above the 4th floor. Window infill panels are aluminium faced polymer foam-filled composite panels-Moore-Bick report of the public inquiry (Fig. 6.1, P. 34) [29]. b Cross section of the window System 5-20 used in the refurbishment of Grenfell Tower [38].

The details of the the window unit structure according to [39] are shown in Fig. 2. The window unit comprises two glazed elements of different size. Different opening configurations are allowed: closed, open, and in-tilt. The right side openning is restricted to $100 \mathrm{~mm}$ openning in the tilt position. The left side casement window pivots around the left side frame column.

\subsection{Failure Modes}

Post-fire observations have shown different failure modes for the windows: inward fallout, outward fallout and partial failure exist at several locations on the Tower. Examples of inward and outward fallout of windows are visible in Fig. 3. However, all the failure modes are quite binary since we observe either a window still in place or no more window. 
(a)

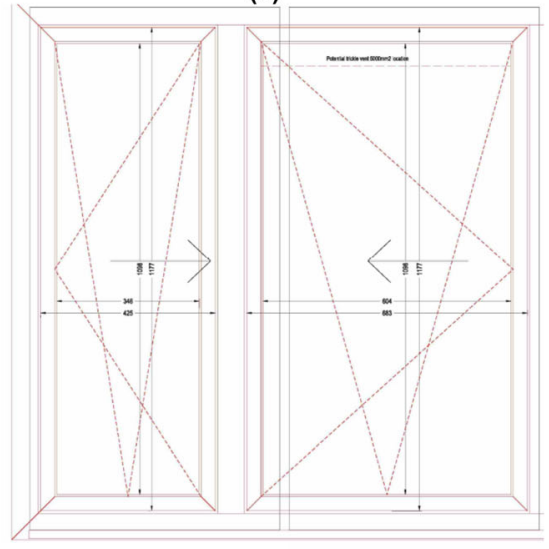

(b)

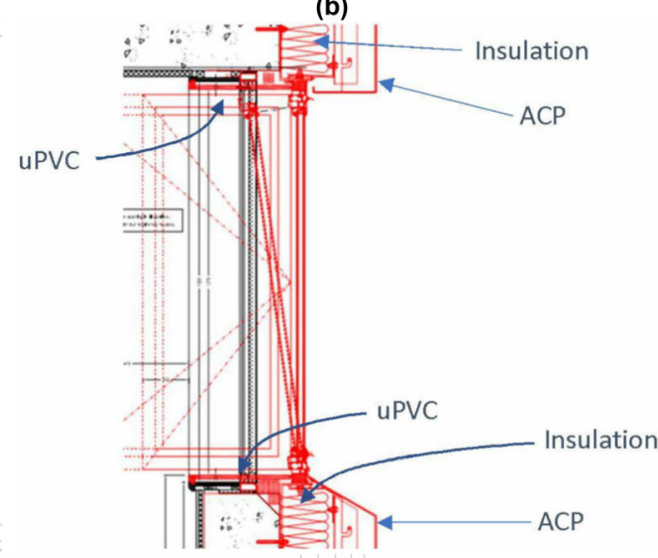

(c)

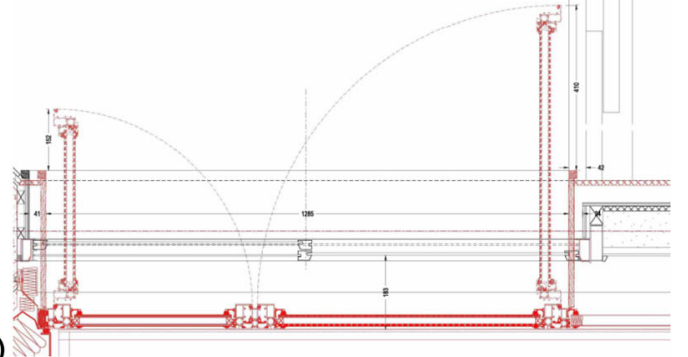

\section{Figure 2. Details of the window system used in the refurbishment of Grenfell Tower a front view, b side view (from J. Torero's expert report [32] Fig. 8, p. 40), c top view.}

As indicated in the introduction section, it is therefore essential to evaluate the conditions that cause the failure of windows for a given fire scenario and enclosure configuration, although the thermal breaking mechanism of glass results from different phenomenon: thermal shock, non-uniform heating or mechanical stress from the distortion of the frame. During the Grenfell Tower fire, the window failure was probably not the only way of flame exit and re-entry, and there was probably more than one window failure mode (Table 1).

The relationship between the initial position of the window casements during the fire (closed, tilted-in) and the window's fallout mode can be questioned, as can the time to failure for a given opening configuration. Open or tilted-in configurations are probable because the Grenfell fire happened during summer, and temperatures close to $20{ }^{\circ} \mathrm{C}$ were recorded during the night of the disaster [40].

The failure of the window can also be due, at first, to the softening and/or melting of the uPVC reveal liner, between the window and the concrete structure, when exposed to heat from the external cladding fire, or to thermally induced breakage of the window glazing. Thus, window fallout was probably not the only way of flame exit and re-entry during the Grenfell disaster. However, the failure 


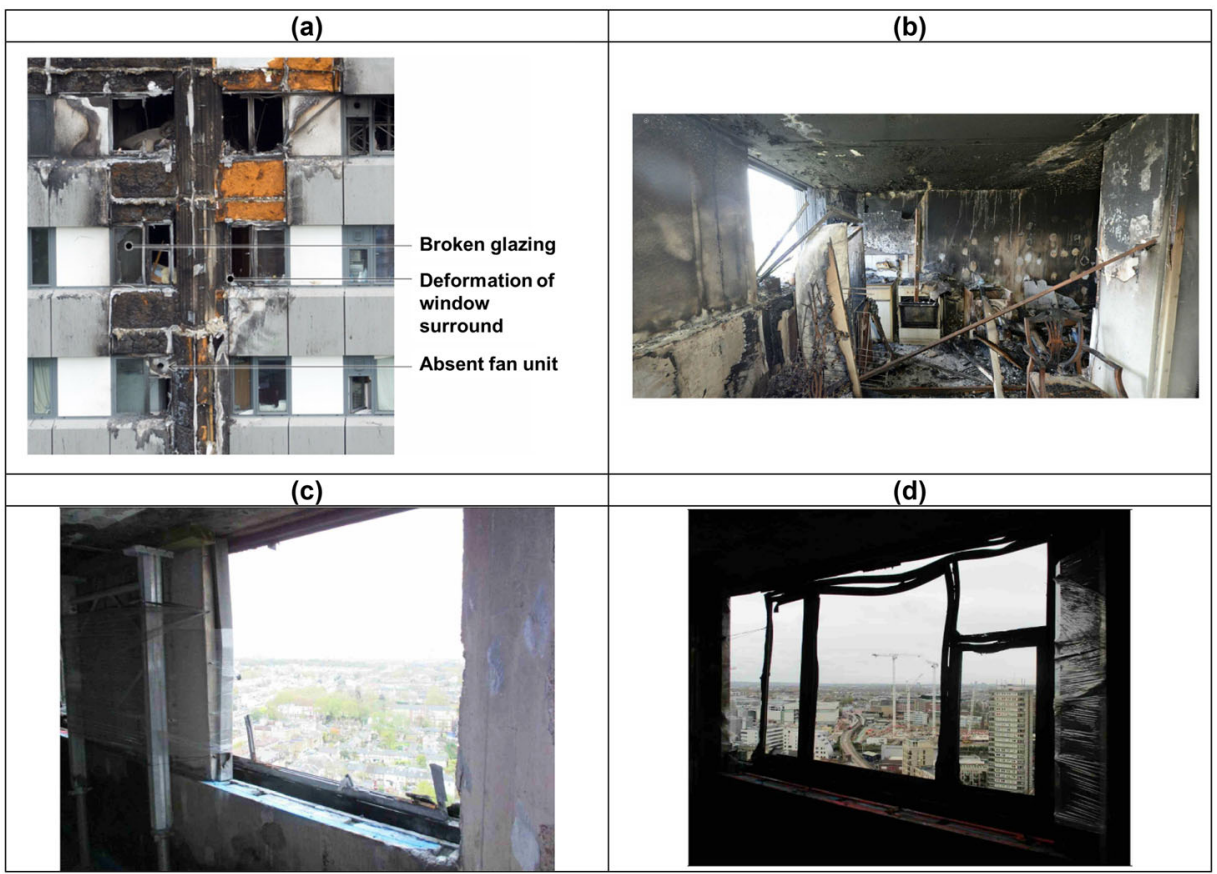

Figure 3. a Failure mode of window frame, L. Bisby's expert report [30], Fig. 11 , p. 166, b Inward failure of window frame, J. Torero's expert report [32], Fig. 54, P. 91, c Outward failure of window frame, B. Lane's expert report, Appendix C [3 1], Table 11 C, p. 94, d Partial failure of window frame, B. Lane's expert report, Appendix C [31], Table $11 \mathrm{C}$, p. 95.

of the window is the phenomenon that led to the most significant influx of smoke and fire effluents into the apartments.

Thus, the present work only investigates frame failure due to the thermal loads induced by the façade fire, and cannot claim to take into account all the events that may have led to window failure.

\subsection{Material Properties}

The exact properties of the glass and polyamide thermal break material used in the Grenfell Tower windows are unknown. Thus, in this work, they are based on literature [15]. Polyamide thermal breaks are produced from glass-reinforced nylon sections designed to withstand temperatures in excess of $200{ }^{\circ} \mathrm{C}$, allowing the composite sections to be powder coated, according to the window manufacturer's website [38]. In general, the loss of thermal properties of polyamide materials varies between $182{ }^{\circ} \mathrm{C}$ and $290^{\circ} \mathrm{C}$ [41]. The polyamide material is modelled with a thermal conductivity of $0.3 \mathrm{~W} \cdot \mathrm{m}^{-1} \cdot \mathrm{K}^{-1}$ and a specific heat of $1600 \mathrm{~J} \cdot \mathrm{kg}^{-1} \cdot \mathrm{K}^{-1}$. 
The density of polyamide is $1490 \mathrm{~kg} / \mathrm{m}^{3}$ [15]. In absence of any available data, the sealing gaskets are assumed to be made from the same polyamide material.

According to the product datasheet, aluminium alloy types 6060T6, T5, or T4 are used to fabricate the window frame. The current computations are performed for aluminium alloy type 6060T6. The thermal properties for 6xxx aluminium alloy are given in [41] and are as follow $\left(0{ }^{\circ} \mathrm{C}<\theta_{\mathrm{al}}<500{ }^{\circ} \mathrm{C}\right)$ :

- thermal conductivity: $\lambda_{\mathrm{al}}=0.07 \theta_{\mathrm{al}}+190\left[\mathrm{~W} \cdot \mathrm{m}^{-1} \cdot \mathrm{K}^{-1}\right]$;

- specific heat: $\mathrm{C}_{\mathrm{p}, \mathrm{al}}=0.41 \theta_{\mathrm{al}}+903\left[\mathrm{~J} \cdot \mathrm{kg}^{-1} \cdot \mathrm{K}^{-1}\right]$; and

- density: $2700\left[\mathrm{~kg} \cdot \mathrm{m}^{-3}\right]$.

A non-linear isotropic hardening law is used to model the aluminium material behaviour. According to [42] the relative thermal expansion of aluminium alloys, $\Delta \mathrm{l} / \mathrm{l}$, is determined as follows:

$$
\Delta \mathrm{l} / 1=0.1 \times 10^{-7} \theta_{\mathrm{al}}^{2}+22.5 \times 10^{-6} \theta_{\mathrm{al}}-4.5 \times 10^{-4}
$$

where, "l" is the length at a temperature of $20^{\circ} \mathrm{C}$ and " $\Delta \mathrm{l}$ " is the expansion due to temperature.

The ratio of the resistance of the aluminium alloy at a given temperature to the resistance at a temperature of $20{ }^{\circ} \mathrm{C}\left(0.2 \%\right.$ proof strength $\left.\mathrm{f}_{0}\right)$ is given in Table 2 .

The melting point for aluminium alloy $6060 \mathrm{~T} 6$ is of $650{ }^{\circ} \mathrm{C}$ [43]. The yield stress (proof stress) for this material is of $150 \mathrm{MPa}$ at ambient temperature for plates thinner than $3 \mathrm{~mm}$ thick [43]. The value for elasticity modulus of aluminium alloys 6060T6 at high temperature, $\mathrm{E}_{\mathrm{al}, \theta}$, is presented in Table 3. Aluminium alloy is modelled as a multi-linear perfectly plastic and isotropic material with the rate dependent plasticity (viscoplasticity), based on the Perzyna model. The Perzyna constitutive model for this case is defined as follows:

$$
\dot{\varepsilon}_{p l}=\gamma \cdot \sqrt[m]{\frac{\sigma}{\sigma_{y}}-1}
$$

where $\sigma$ and $\sigma_{y}$ are respectively the effective stress and the static yield stress, $\dot{\epsilon}_{p l}$ is the equivalent plastic strain rate, $m$ is the strain rate hardening parameters and $\gamma$

\section{Table 2}

\section{Ratio of the resistance of aluminium alloy (0.2\% proof strength) at a given temperature to the resistance at a temperature of $20^{\circ} \mathrm{C}$ [42]}

\begin{tabular}{lccccccccc}
\hline & & \multicolumn{7}{c}{ Temperature of the aluminium alloy $\left({ }^{\circ} \mathrm{C}\right)$} \\
\cline { 3 - 10 } Alloy & State & 20 & 100 & 150 & 200 & 250 & 300 & 350 & 400 \\
\hline EN AW-6060 & T6 & 1 & 0.91 & 0.84 & 0.71 & 0.38 & 0.19 & 0.09 & 0 \\
\hline
\end{tabular}




\section{Table 3 \\ Elasticity modulus for aluminium alloy as a function of the temperature [42]}

\begin{tabular}{l}
$\begin{array}{l}\text { Temperature of } \\
\text { the aluminium } \\
\text { alloy }\left({ }^{\circ} \mathrm{C}\right)\end{array}$ \\
\hline $\begin{array}{l}\text { Elasticity modulus } \\
(\mathrm{MPa})\end{array}$
\end{tabular}

is the material viscosity parameters. The value for $m$ and $\gamma$ are respectively set to 0.24 and 9 [44]. Aluminium maximum strain is estimated to 0.108 [42].

The emissivity of the material surface is required also for thermal analysis when radiation exchanges are significant. The surface emissivity is 0.7 for the aluminium parts [42] and 0.85 for polyamide materials [45]. The surface emissivity for glass varies between 0.86 and 0.92 [46].

\section{Thermal Analysis of the Window Frame}

The initial fire, before break-out from the flat of origin, was localized close to the wall and window, in the southeast corner of the kitchen of Flat 16, located on the 4th floor of the East façade of Grenfell Tower. The fire development analysis performed in [34] with the CFD code FDS was dedicated to the fire development inside the initial apartment (Flat $16,4^{\text {th }}$ floor), and to the fire spread over the façade to the apartment above (Flat 26, $5^{\text {th }}$ floor). It allowed the evaluation of the heat fluxes imparted to each part of the window frame modelled, which comprised aluminium and polyamide thermal breaks. In the present study, these heat fluxes are applied as boundary conditions on the exposed parts of the thermal model.

\subsection{Model Description}

Thermal analysis consists in computing the material warming due the thermal loads obtained from the modelling of the real fire scenario. This analysis is performed with ANSYS Mechanical APDL [37] using two-dimensional (2D) PLANE55 thermal planar elements. The analysis is linked to the equations solving heat conduction within the solid, convection and radiation in the cavities, and heat transfer at inner and outer boundaries between the solid and ambient environment via convection and radiation.

Both frame and casement sections of the window are modelled. A part of the glass, which participates as an interface between the two components of the window casement, is also modelled. Figure 4 shows the geometry used in the thermal model. 


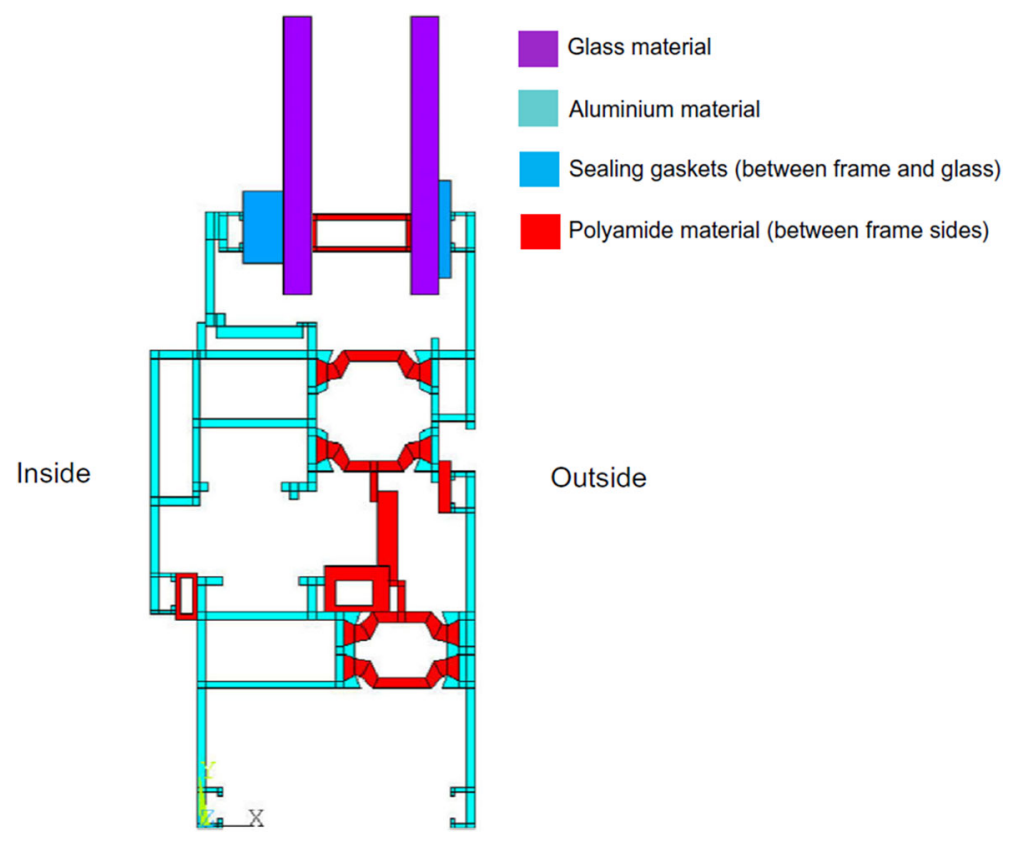

Figure 4. Geometry of the window frame and casement that was used in the thermal model.

\subsection{Thermal Boundary Conditions Representative of the Fire}

The thermal loads in terms of Gauge Heat Flux (GHF) were evaluated during the previous CFD simulation in [34]. Figure 5 illustrates the temperatures to which

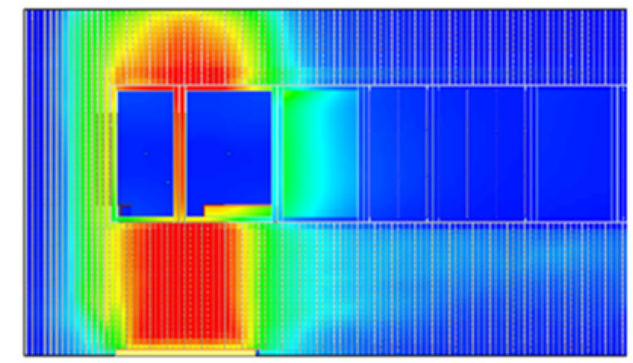

$\begin{array}{llllllllllll}0 & 65 & 130 & 200 & 265 & 330 & 400 & 465 & 530 & 600 & 660 & {\left[{ }^{\circ} \mathrm{C}\right]}\end{array}$

Figure 5. Numerically modelled temperafure of the external window on the 5th floor, directly above Flat 16 of the Grenfell Tower, after $4 \mathrm{~min}$ of façade fire exposure [34]. 
the external frame of the window located at the $5^{\text {th }}$ floor, directly above Flat 16 , were subjected after $4 \mathrm{~min}$ of façade fire exposure. The heat flux fields applied to the exposed face of the window are addressed in Fig. 6a. The position for each part of the window is indicated in Fig. 6b. These thermal loads are representative not only of fire break-out through a typical window, but also of the developed façade fire during vertical fire spread over the tower, as observed in Fig. 7. At later stages of the façade fire, the numerically estimated thermal loads (in terms of gauge heat flux) on window frames are consistent with the general flux evolution indicated in Fig. 6. The maximum heat fluxes imparted to Parts 1, 5 and 7 of the window frame (Fig. 6b) is about $120 \mathrm{~kW} / \mathrm{m}^{2}$ after 3-4 min of fire exposure, while the minimum heat fluxes evaluated for the lower Parts 2 and 6 and lateral Part 3 of the window frame (Fig. 6b) are between 30 and $70 \mathrm{~kW} / \mathrm{m}^{2}$. There are differences for the windows attacked thermally during horizontal fire spread where thermal gradients can change slightly. Flames affect Part 8 of the frame before Part 5 (Fig. 6b) but the delay in such horizontal gradients is less than 1 min.

For the outer and inner faces of the window, the heat transfer coefficient (film coefficient) is taken from the CFD simulation (see Fig. 8). As shown in Fig. 8, the coefficient ranges between 10 and $15 \mathrm{~W} \cdot \mathrm{m}^{-2} \cdot \mathrm{K}^{-1}$ for the exposed side of the window, where the flow is turbulent, and is about $4 \mathrm{~W} \cdot \mathrm{m}^{-2} \cdot \mathrm{K}^{-1}$ at unexposed side of the window.

In the window cavities, the flow is quasi-laminar, because of the slow air motion. The value for the coefficient in the cavities is then set to $4 \mathrm{~W} \cdot \mathrm{m}^{-2} \cdot \mathrm{K}^{-1}$, which is also emphasised in Eurocodes [47]. However, a sensitivity analysis on this parameter is addressed in the next section.

\subsection{Numerical Setup}

The thermal simulations are set up in $2 \mathrm{D}$, because the out-of-plane distribution of boundary conditions applied at each part on window is uniform. Therefore, out-

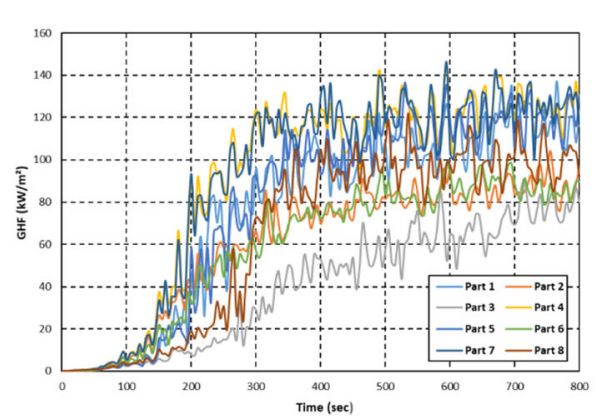

(a)

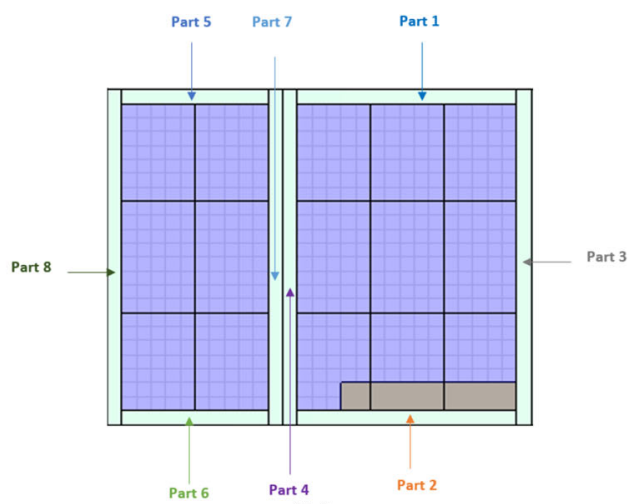

(b)

Figure 6. Heat fluxes to which the outer face of windows were exposed for all sections of the frame-Position of each window frame section [34]. 


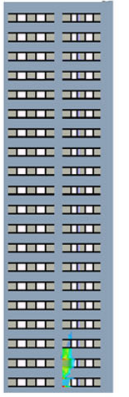

01:15

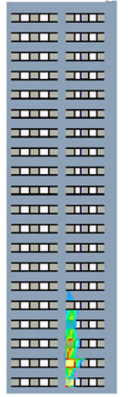

$01: 18$

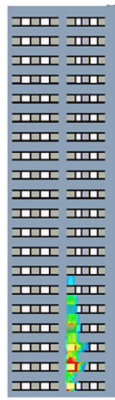

01:19

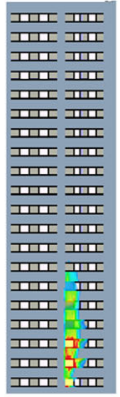

01:20

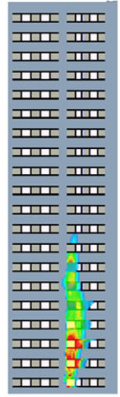

01:22

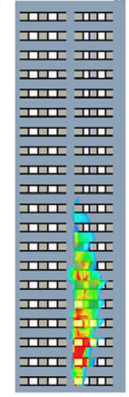

01:23

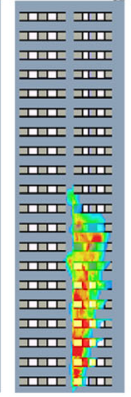

01:24

Figure 7. Heat fluxes to which the outer face of windows were exposed during vertical fire spread over the East face of Grenfell Tower [36].

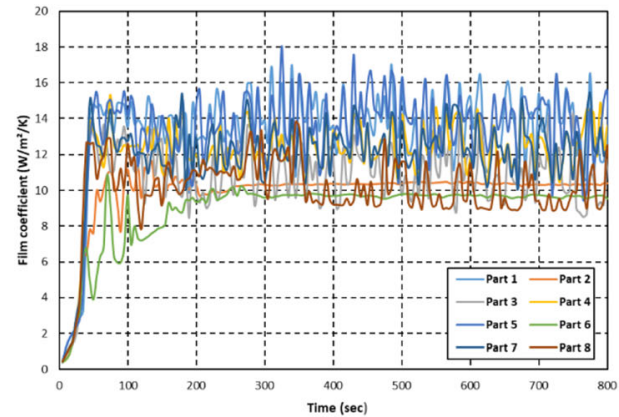

(a)

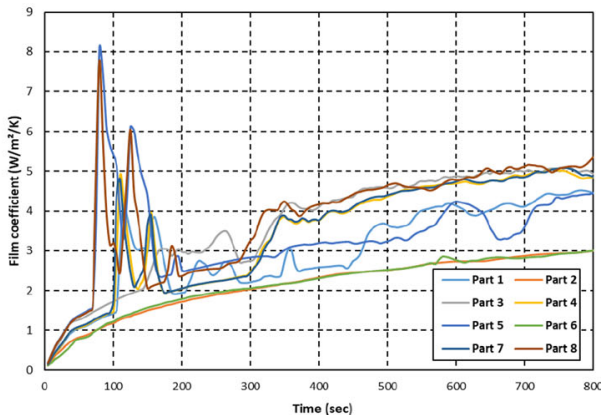

(b)

Figure 8. Evolution of the convective coefficient applied to the exposed (a) and un-exposed (b) faces for all sections of the window frame.

of-plane heat flow is insignificant. This assumption is valid except for the junctions of head jambs and side jambs of the window. However, this effect remains local and out-of-scope of the current study.

As shown in Fig. 9, two layers of SURF151 elements are modelled and superposed on the exposed faces of the windows, to apply both heat flux and temperature conditions at the surface of the materials. The heat flux fields derived from the FDS code [34] are applied to the first layer of surface elements. As the thermal loads are given in terms of Gauge Heat Flux (GHF), ambient temperature is also applied to the second layer of surface elements at their exposed face. The unexposed face is modelled with surface layer elements to apply in-room (ambient) temperature conditions. The temperature of London city was approximately $16{ }^{\circ} \mathrm{C}$ at 00:50 AM on June, 14th 2017 [40]. In the absence of in-room and precise 


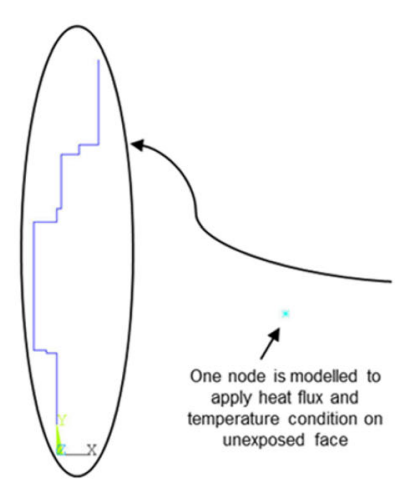

Un-exposed face

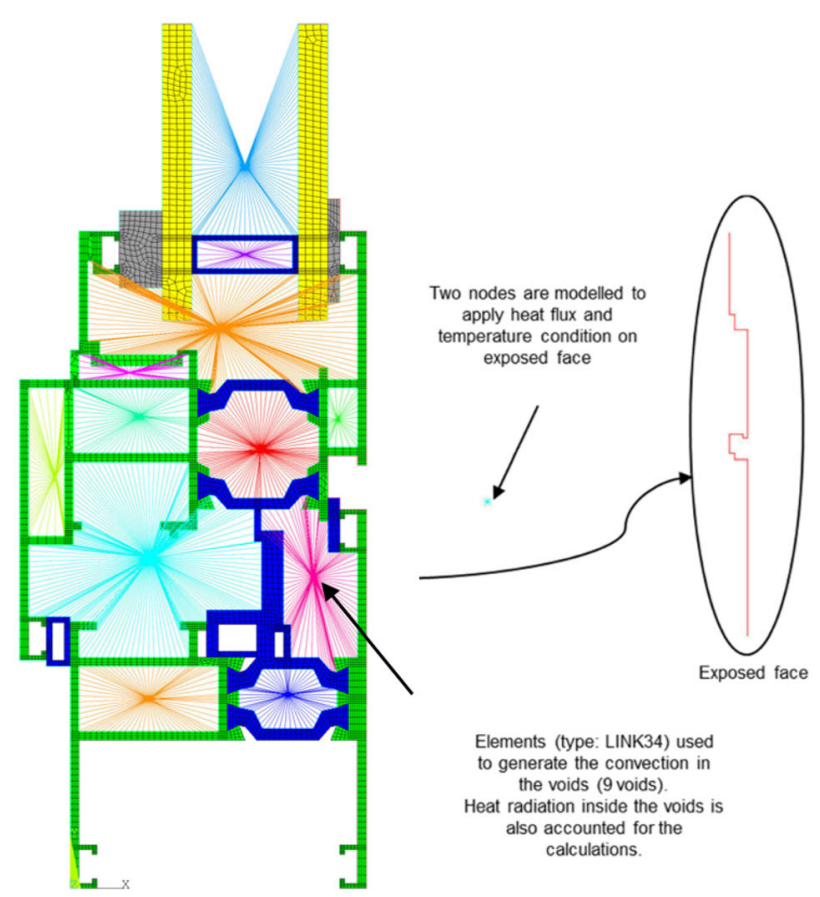

\section{Figure 9. Boundary conditions applied to the thermal model of the window and frame.}

external temperature data, the initial ambient temperature is fixed as $20{ }^{\circ} \mathrm{C}$ on both sides of window.

Convective heat exchange and surface-to-surface radiation were modelled for the cavities inside the frame. Air motion inside the cavities is ignored. Therefore, the convection is modelled using link elements (LINK34) connected to a node, which represents the cavity temperature. Convection element parameters are fixed regarding exchange surfaces in the cavities. For these elements, the convection exchange is defined as follows:

$$
q=h_{f} A \cdot E \cdot\left(T_{i}-T_{j}\right)
$$

where $q$ is the heat flow rate $\left(\mathrm{W} \cdot \mathrm{m}^{-2}\right), h_{f}$ is the convective heat transfer coefficient (film coefficient- $\mathrm{W} \cdot \mathrm{m}^{-2} \cdot \mathrm{K}^{-1}$ ), $A$ is the element area $\left(\mathrm{m}^{2}\right)$ and $\mathrm{E}$ is the empirical convection term [37]. $T_{i}$ is the temperature for the end node of the link at the surface of the cavity. $T_{j}$ is the bulk temperature in the cavity, which correspond to the temperatures at the share nodes of all the links. The area of the link elements is computed based on the participating area of the surface elements in the void volume, which are connected to each link. 


\subsection{Sensitivity Analysis of the Convective Exchanges Inside the Cavities}

Classical finite element approaches are not adapted to model airflow where finite volume approaches are used. However, some alternative approaches are used to model the stationary airflow. As shown in the previous section, ANSYS convective LINK34 elements are used to model the convection mechanism of heat transfer. In order to evaluate the computations, their results are compared with a second thermal analysis performed using SURF151 elements for convection in the cavities. In this analysis, the average temperature of the cavity is applied to the bulk nodes before each step of the computations. Radiation and convection in the cavities are computed at each time-step based on this temperature. The cavity temperatures are compared for both models based on the inputs, heat fluxes and film coefficients, applied to part 1 of the window (see in Figs. 6, 8). The analysis is performed for $840 \mathrm{~s}$. Figure 10 shows the comparison between these two set of results. The Pearson correlation coefficient (PCC) is 0.986 and the relative error (RE) between two set of results for $840 \mathrm{~s}$ of computation is of $1.3 \%$.

$$
\begin{aligned}
& P C C=\frac{\operatorname{COV}\left(T_{M 1}, T_{M 2}\right)}{\sqrt{\operatorname{Var}\left(T_{M 1}\right) \cdot \operatorname{Var}\left(T_{M 2}\right)}} \\
& R E=\frac{\sum_{i}\left(T_{M 1}^{i}-T_{M 2}^{i}\right)^{2}}{\sqrt{\sum_{i} T_{M 1}^{i} \sum_{i} T_{M 2}^{i}}}
\end{aligned}
$$

where $T_{M 1}$ and $T_{M 2}$ respectively represent the cavity temperatures for the computations from the model generating the convection in the cavities by LINK34 ele-

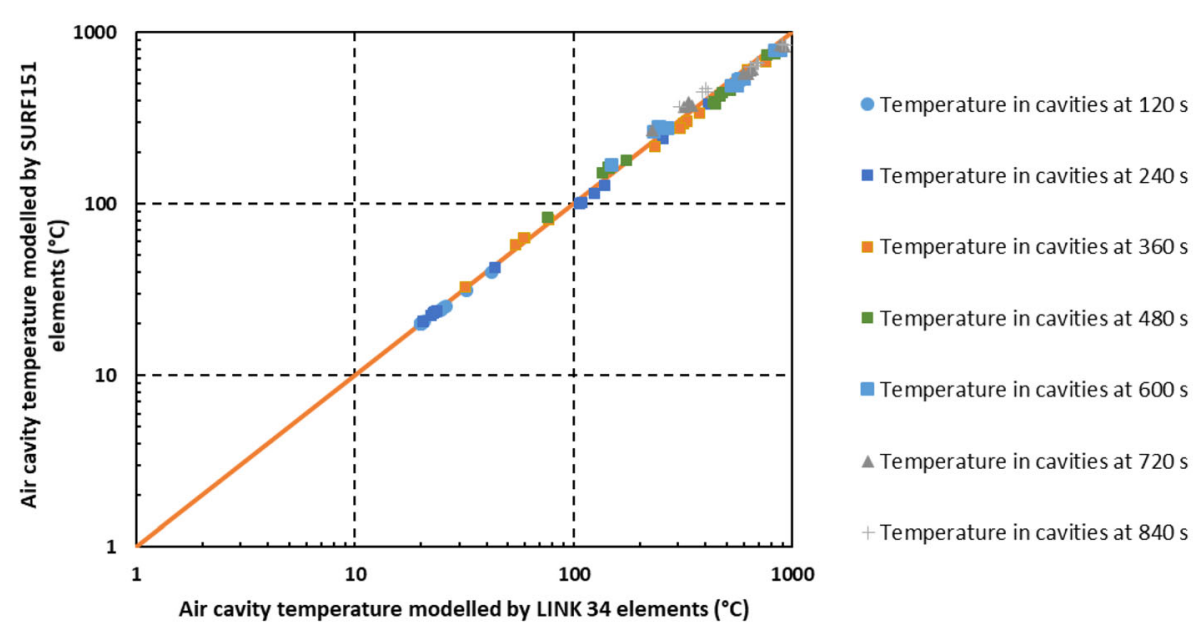

Figure 10. Comparison between the bulk temperatures for the modelling of convection by LINK34 elements versus SURF 151 elements in the cavities of the window frame. 
ments and the model generating the convection in the cavities by SURF151 elements.

This shows the slight impact of the elements used for the convective exchanges on the temperature results.

A sensitivity analysis is performed for the convective coefficient in the cavities, for window Part 1 (see in Fig. 6b). Heat fluxes and adapted exchange coefficients are applied to the exposed faces (see in Figs. 6 and 8). Figure 11 presents the average temperature in all cavities at $300 \mathrm{~s}, 600 \mathrm{~s}$ and $900 \mathrm{~s}$. The computations show that the variation of film coefficient in the cavities for this study may be neglected. The average increase of the temperature in a cavity for an increase of $1 \mathrm{~W} \cdot \mathrm{m}^{-2} \cdot \mathrm{K}^{-1}$ of film coefficient is about $0.46^{\circ} \mathrm{C}$ at $300 \mathrm{~s}$ and $1.08{ }^{\circ} \mathrm{C}$ at $900 \mathrm{~s}$.

\subsection{Thermal Analysis}

Time-history temperatures are evaluated for all of the frame sides (Parts 1 to 8). Temperatures at four locations A, B, C and D, located close to the polyamide thermal breaks, are indicated in Fig. 12. Temperatures are up to $80{ }^{\circ} \mathrm{C}$ between 1.5 min (on Parts 4 and 8) and 2.5 min (on Part 3) of external fire exposure of the polyamide thermal breaks, and up to $200{ }^{\circ} \mathrm{C}$ between 2 min (on Parts 4 and 8) and $4.5 \mathrm{~min}$ (on Part 3) of exposure for all positions close to the external side. This is consistent with the numerical observations in [34] where the external fire breaks the left part of the window first. Therefore, the thermal failure of the window frame is expected before $5 \mathrm{~min}$ of external fire exposure. This is consistent with the criterion of $4 \mathrm{~min}$ for the partial window failure considered in the fire model [34].

The thermal fields at all sides of the window frame at $180 \mathrm{~s}(3 \mathrm{~min})$ of fire exposure are addressed in Fig. 13. The temperature is at about the melting point $\left(650^{\circ} \mathrm{C}\right)$ at the exposed side of Parts 4,7 and 8 . The results show also that the

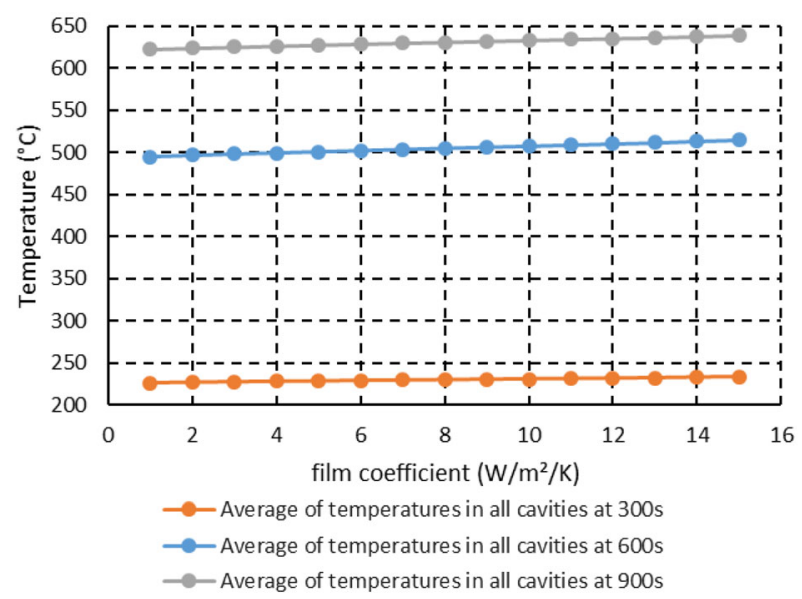

Figure 11. Average temperature in all cavities of the window frame at $300 \mathrm{~s}, 600 \mathrm{~s}$ and $900 \mathrm{~s}$. 


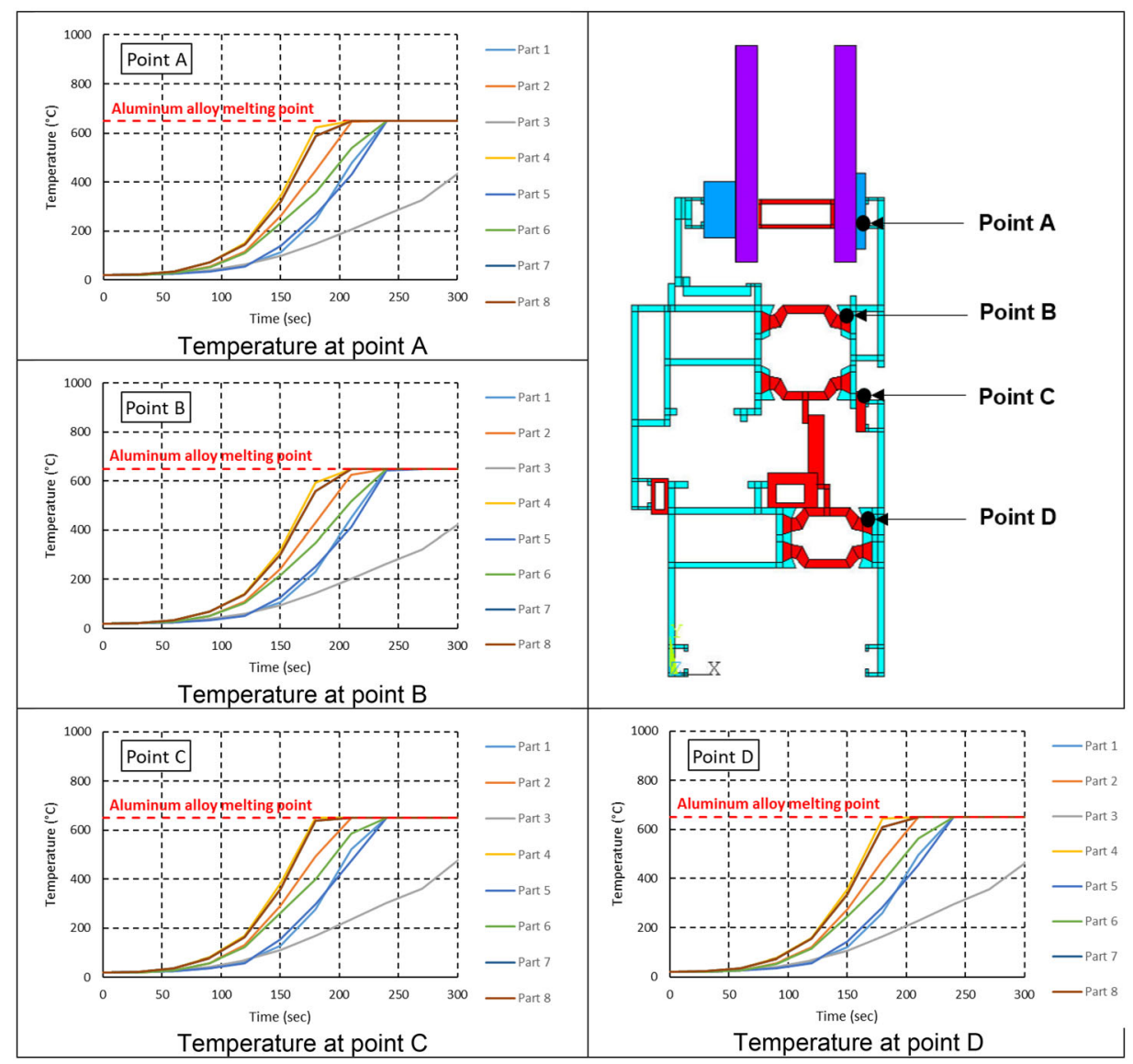

\section{Figure 12. Temperafure over time, evaluated at four locations (A, B, C and D) in the window frame.}

exposed side of the window has been melted at all parts except Part 3 before about 4 min.

However, the failure time of the aluminium frame is defined as the instant at which the temperature of the thermal break has reached its melting temperature, as indicated in [15]. The failure of the window can also be due to additional events, such as the softening and/or melting of the uPVC reveal liner when exposed to heat from the external cladding fire, or to thermally-induced breakage of the window glazing.

The results of the above thermal analysis (called thermal analysis type 1) of the exposed face shows that the exposed side of window melted partially or totally at about 3 min (for Parts 4 and 8), as the melting point of aluminium alloy 6060T6 is lower than $650{ }^{\circ} \mathrm{C}$. The thermo-mechanical analysis in the next section, confirms that the external profile of the window frame may be removed after about $3 \mathrm{~min}$ (173 s), because of large deformations and failure of this side of window. 


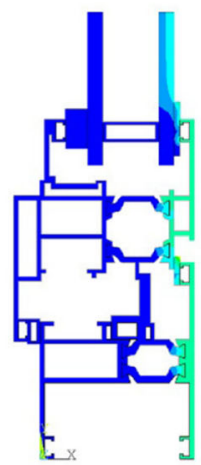

Part 1

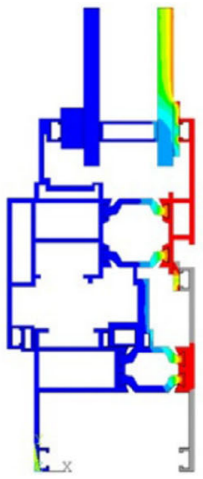

Part 4

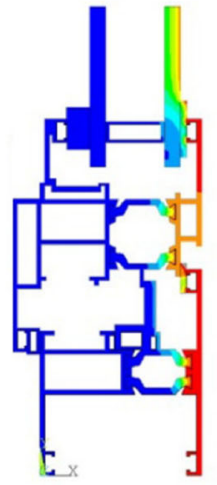

Part 7

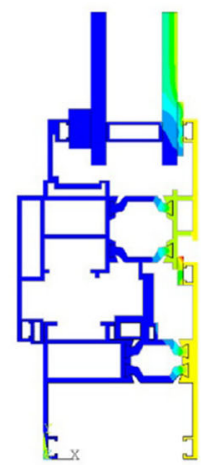

Part 2
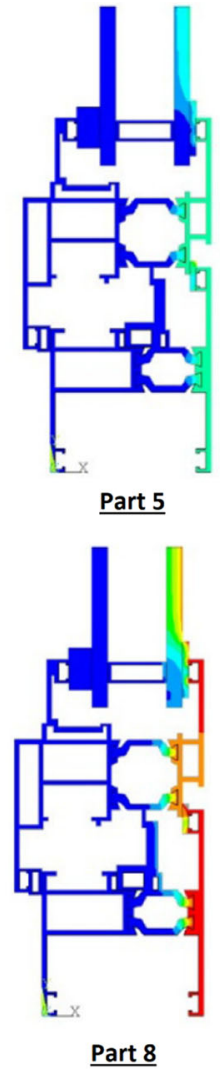

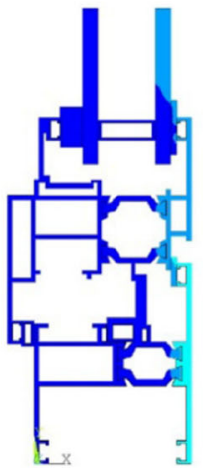

Part 3

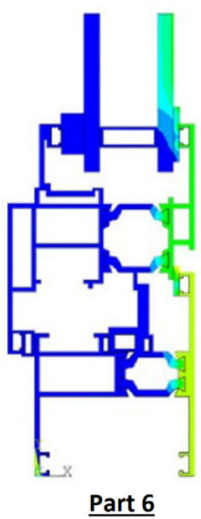

Temperature $\left[{ }^{\circ} \mathrm{C}\right]$

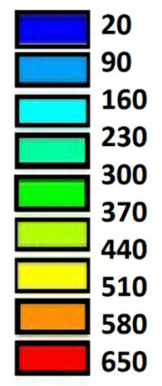




\section{Figure 13. Temperature fields for different locations in the window frame at $180 \mathrm{~s}$ of fire exposure.}

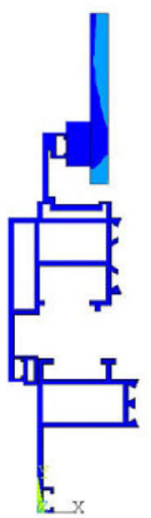

(a) Thermal analysis type 1

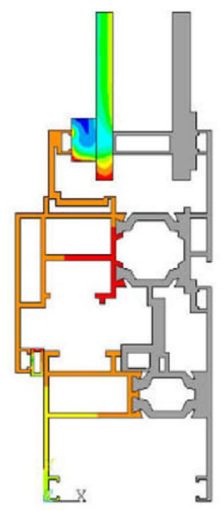

Temperature $\left[{ }^{\circ} \mathrm{C}\right]$

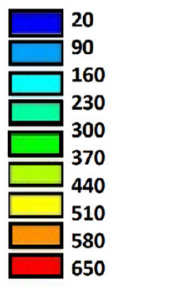

(b) Thermal analysis type 1

\section{Figure 14. Temperature fields at $240 \mathrm{~s}$ of fire exposure for the inner section of Part 8-(a) with external section in place (b) without the external section.}

The thermal heating of the internal profile of the window frame, in the above model, is no longer valid after the failure of the outside section of the frame.

Therefore, a new thermal analysis was set up (called thermal analysis type 2). The outside section of the window frame wall is deactivated. Surface boundary elements and conductive elements are removed (so called killed) during the analysis. Then, the new boundary surface elements are created (so called birth) on the inner face of the internal profile at $3 \mathrm{~min}$. The thermal fields for Part 8 of the window frame at $240 \mathrm{~s}$ of fire exposure are shown in Fig. 14. Figure 14a shows the temperature field on internal profile of the window frame at $240 \mathrm{~s}$, assuming that the external profile resists thermal heating (thermal analysis type 1). The maximum temperature is lower than $90^{\circ} \mathrm{C}$ for the inner profile of Part 8 at this time. Figure $14 \mathrm{~b}$ shows the temperature field of internal profile of the window frame at $240 \mathrm{~s}$, assuming that the external profile fell away or melted at 3 min (thermal analysis type 2). The temperature of the internal profile, when the external profile has fallen away or melted, indicates that the internal profile may well melt or fall away before 4 min (240 s).

As discussed previously, the external profile may stay in place for some window parts until 4 min have elapsed, i.e. 1 min later than the time used for resetting the thermal analysis type 2 . Therefore, the window may survive until 5 min $(300 \mathrm{~s})$, because the heating of the internal profile of the window may be delayed by about $1 \mathrm{~min}$. 
Figure 15 shows the comparison between the temperatures at different points of the window frame for the two types of thermal analysis described above. The temperature is higher than the aluminium alloy melting point (with upper limit of $650{ }^{\circ} \mathrm{C}$ ) at $180 \mathrm{~s}$ for point $\mathrm{E}$ for analysis type 1 . However, the analysis type 2 assumes that the external profile of the window fails and the temperature at this point does not increase anymore. On the contrary, the computations show that the temperatures are higher after $180 \mathrm{~s}$ for points $\mathrm{F}, \mathrm{G}$ and $\mathrm{H}$. The results of thermal analysis show that the failure of the internal profile of the window frame occurs at about $4 \mathrm{~min}(250 \mathrm{~s})$, because of aluminium alloy melting.

\section{Structural Analysis of the Window Frame}

\subsection{Numerical Setup}

The structural behaviour of the window frame when subjected to thermal loads from the fire model is investigated. The thermomechanical model used is purely non-linear because of geometrical, material and contact between the different surfaces.

The proposed structural model uses SHELL 181 elements. These elements are compatible with layered structures and may produce the plate buckling effect during the analysis. The frame cross section has been modelled with 56 nodes in order to obtain an accurate shape and temperature distribution for the mechanical analysis. The temperature of the aluminium frame at each position is mapped from the thermal analysis.

The polyamide thermal breaks have not been modelled in the mechanical computation due to their poor rigidity resistance compared with the aluminium alloy at any temperature, and negligible fire performance. Although the polyamide has good tensile strength at low temperatures (about 60-70 MPa), the rigidity of these materials is generally low. As an example, the Young modulus of polyamide
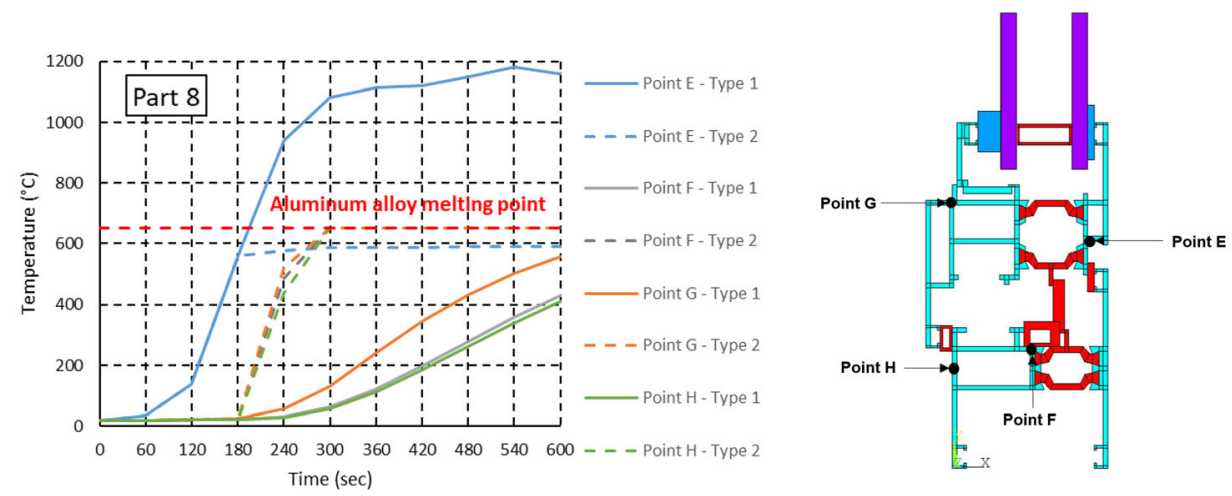

Figure 15. Evolution of temperature at exposed and on exposed side of frame part 1 at 600 s of fire exposure for two types of thermal analysis. 
Nylon6 is about $160-300 \mathrm{MPa}$ [48], which is less than $1 \%$ of Young modulus of the aluminium alloy. The loss of thermal properties of polyamide materials occurs close to $200{ }^{\circ} \mathrm{C}$, which is a very low temperature compared with the temperature at which the frame failure occurs. Therefore, the structural modelling of this material does inform the failure mode.

The window structure comprises the frame, the casements, the solid walls and the contact element between the walls and the frame. Both frame and casements are modelled. The numerical model consists of the following element types (Fig. 16):

- SHELL181 to model aluminium material;

- SOLID185 to model the semi-rigid part for the lateral studs;

- CONTA174 and TARG170 to model the contact surfaces between the frame and the wall; and

- LINK180 used for the tilt-in window condition.

\subsection{Boundary Conditions and Loads}

Two opening configurations of the window casements are investigated, and consist respectively of "closed" and "tilted-in" positions. The gravity load is represented by a downward acceleration of $\mathrm{g}=9.81 \mathrm{~m} \cdot \mathrm{s}^{-2}$ in order to model the weight of the aluminium. The weight of the double glazed unit is distributed uniformly in the casement. Thus, the weight of the glass is applied uniformly over all sides of the casements. The double glazed unit is not modelled in the structural analysis. Indeed, it is difficult to imagine that its dilation would cause failure of the frame because of its spatial positioning which is in the plane of the window. Further-

(a)

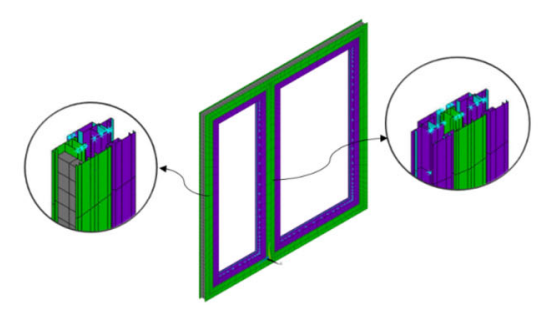

(b)

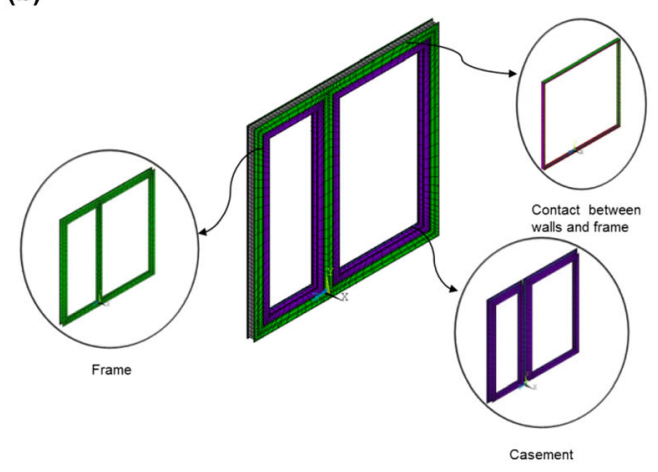

Figure 16. Details of the geometry for the structural analysis a frame, b frame and casement contacts. 
more, additional dilation in the glass may cause the local fractures during the fire, which would dissipate the dilatation forces.

The model boundary conditions and loads are summarised in Fig. 17.

Two nodes, one located on the frame and another one located on the casement, which are along the line over the vertical jambs (for side hang) or horizontal jamb (for bottom hang), are coupled and used to model the hinges. The coupling of the nodes between the frame and the casement at the position of window hinges generates the closing condition for the closed window configuration. The closing conditions are not implemented for the tilted-in window configuration. As the
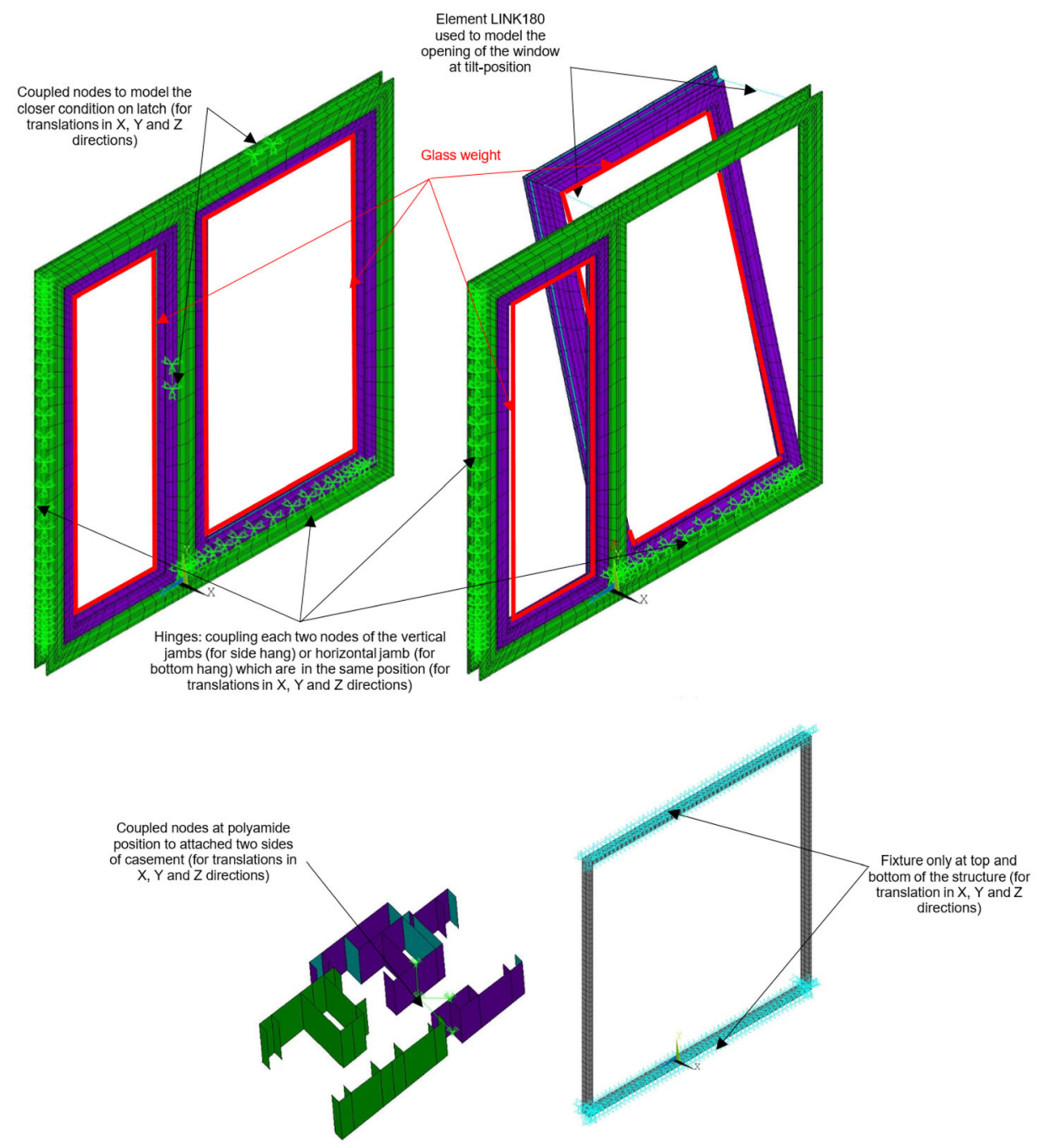

Figure 17. Loads and boundary conditions for the closed (top) and the tilted-in (bottom) opening configurations of the window. 
polyamide thermal break is not modelled, both sides of the casement are linked at different points (two points on each jamb of casement) to generate the global stability of the numerical model. The boundary at the position of uPVC framing is fixed in three principal directions.

The effect of wind on the window is neglected because the window is at the East side of the building, while the wind was coming from SSW direction the night of the fire [40]. The wind velocity was $4 \mathrm{~km} \cdot \mathrm{hr}^{-1}$ on June $14^{\text {th }} 2017$ between mid-night and 06:00AM [40]. Note that the wind load does not exceed $1.5 \mathrm{~N}$ [49] for the windows facing the wind, which are located in the south side of the building.

\subsection{Thermo-Mechanical Analysis for the Closed Window}

The thermomechanical modelling shows high deformation of the external profile of the window at about $3 \mathrm{~min}(173 \mathrm{~s})$.

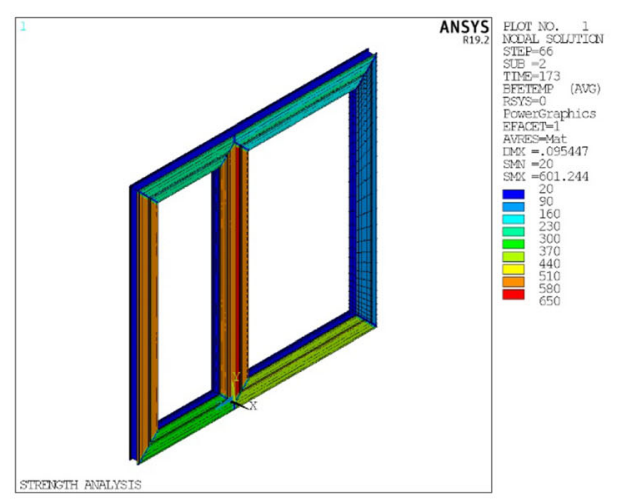

(a) Window temperature

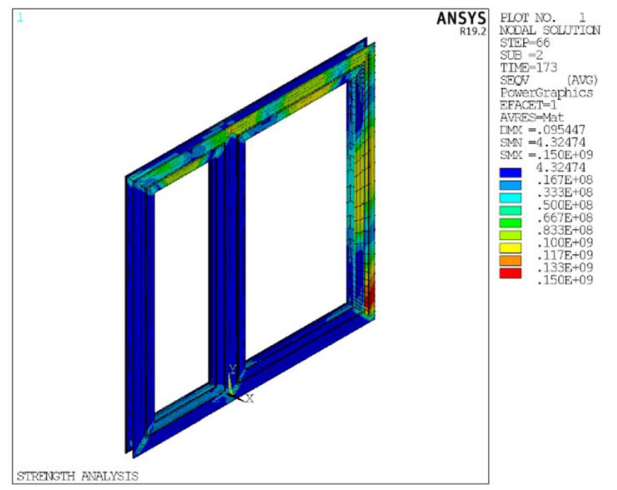

(c) Von Mises equivalent stress

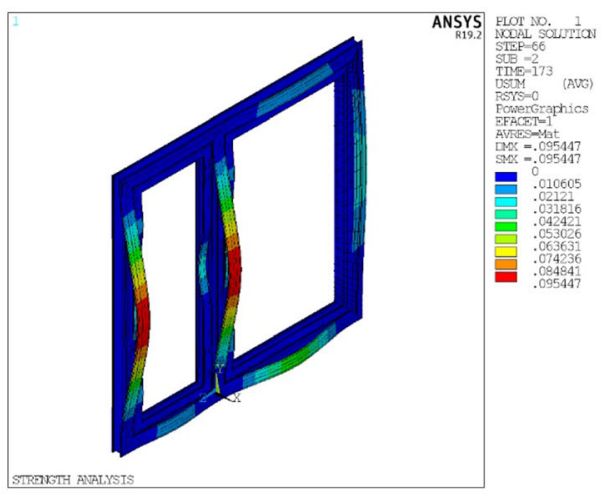

(b) Window deformation

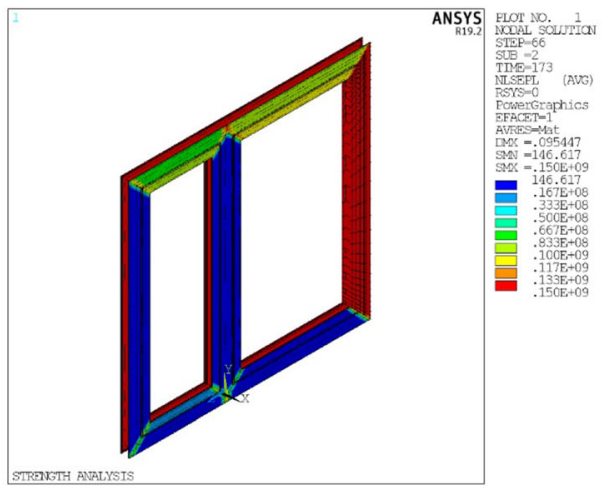

(d) Plastic equivalent stress

Figure 18. Frame temperafure (a), deformation (b), Von Mises stress (c) and plastic equivalent stress (d) before the failure of the outer frame at $173 \mathrm{~s}$ of fire exposure for the closed window configuration. 
Figure 18a gives the temperature of different Parts of window. These temperatures are computed by $2 \mathrm{D}$ thermal analysis. The temperature is almost uniform through the Aluminium thickness. The temperature fields are mapped from the 2D thermal model to the 3D mechanical model in 56 layers through the cross sections for each Part of the window. The temperature on the left side of the frame is indeed lower than the one on the middle component. This is due to the presence of the column located nearby the left part of the window. The vertical flames venting out the lower flat window are impinging the façade above but are deviated by the column having a triangular shape. The flames reattached to the column, leading to lower temperature on the left side of the window that can be considered "shaded" while the flame attached along the column. Convective effects are thus enhanced at this location. The vertical outer profiles of the frame are deformed and may be detached from the rest of the structure because of the large deflections as shown in Fig. 18b. The left side of the exposed frame plasticised because of the thermal stress (Fig. 18c). Aluminium alloy's yield stress decreases at high temperature. The material resistance is totally removed at the bottom and left side of the window (Fig. 18d). At this moment, the outer profile of the frame detaches from the rest of the window and falls outward. The dynamic force due to the weight of the outer profile and casement may lead to its outward failure.

Thus, even if a part of the window frame stays in place, the glass breakage is almost certain at this moment, because it will fall out when the frame no longer holds it in place.

If the external profile of the window collapses without pulling the whole window out, the inner profile will fail inward. The modelling results show the collapse of the inner profile of the frame at about $4 \mathrm{~min}$ (238 s) of fire exposure. Figure 19 refers to the temperature, deformed shape, Von Mises stress and plastic equivalent stress for the window before the collapse of the inner profile. The modelling yields a maximum internal profile temperature of up to $600{ }^{\circ} \mathrm{C}$ when the failure occurs for the external profile. At this time, almost all of the left side of the structure plasticised, which leads the window collapse.

\subsection{Thermo-Mechanical Analysis for the In-Tilt Window}

The structure is set-up to simulate the window in a tilted-in state. For this configuration, the side turn casement is unlocked, in order to see the effect of its opening on the failure.

Temperature loads are applied to all Parts of the window except the tilted casement. The outer profile detaches from the rest of the window and falls outward after approximately $3 \mathrm{~min}$ (174 s) of fire exposure. The failure mode of the outer profile of the tilted-in configuration is the same as that of the closed window configuration. The maximum temperature at failure time is about $610{ }^{\circ} \mathrm{C}$ on the central vertical frame Parts (Parts $4 \& 7$ ). Figure 20 shows that the vertical frame Parts are deformed and may be detached from the rest of the structure because of the large deflections. The left side of the exposed frame plasticised because of the thermal stress. However, the failure of the outer profile of the window does not cause the failure toward outside because the weight of the tilted-in casement stabi- 


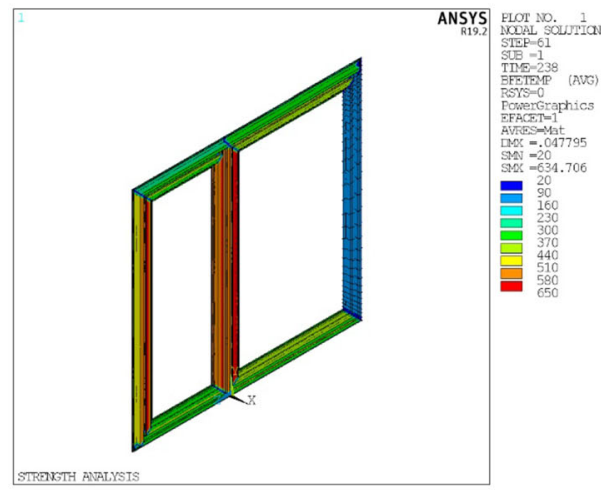

(a) Temperature at internal wall

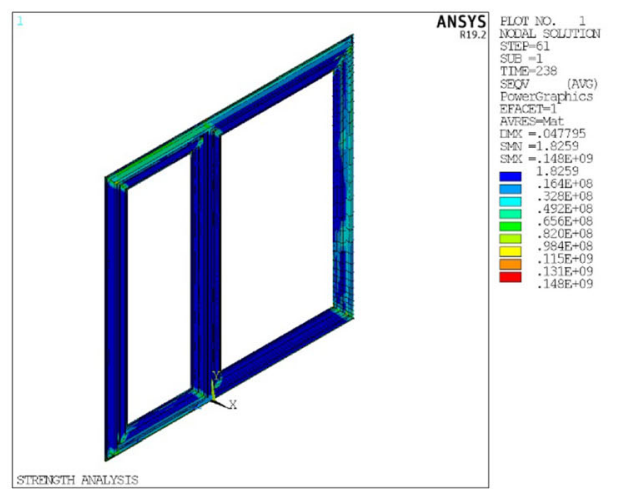

(c) Von Mises equivalent stress

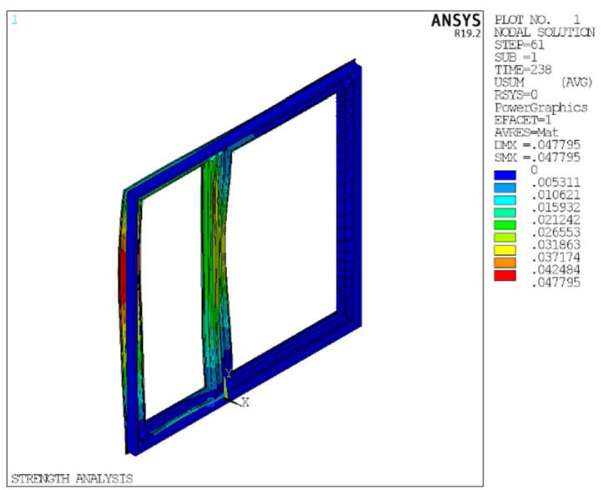

(b) Window deformation

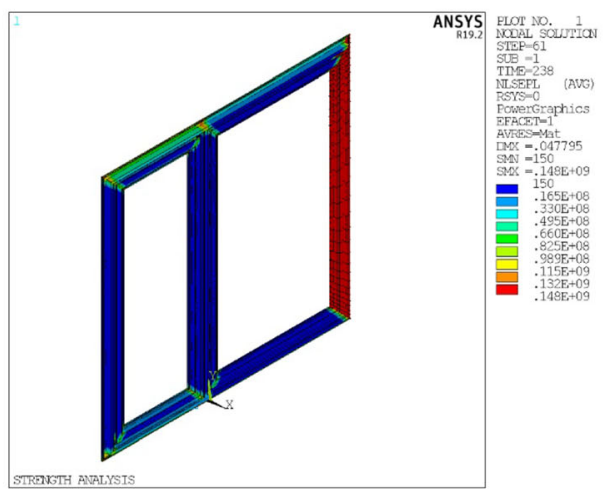

(d) Plastic equivalent stress

Figure 19. Frame temperature (a), deformation (b), Von Mises stress (c) and plastic equivalent stress (d) before the failure of the inner frame at $238 \mathrm{~s}$ of fire exposure for the closed window configuration.

lizes the frame and prevents this mode of failure. Even if a part of the window frame stays in place, the glass breakage is almost certain at this time, because of the large deformation of the frame leading to mechanical stress, or because it will fall out when the frame no longer holds it in place.

The inner profile will collapse inwards. Modelling shows that the window is deformed and the side-hung casement opens toward inside at about $3.5 \mathrm{~min}$ (203 s) of fire exposure. The opening of the side-hung casement, shown in Fig. 21, may generate additional dynamic force on the window and create the complete failure of the structure at this moment. This scenario may occur because the internal frame cannot resist horizontal loads after removing the external profile. However, the numerical model no longer converges at this point, because of large deformation and numerical instability of the finite element solution.

The hypothesis of collapse due to the opening of the side-hung casement may be rejected, because the temperature field evaluated for the internal profile at this 


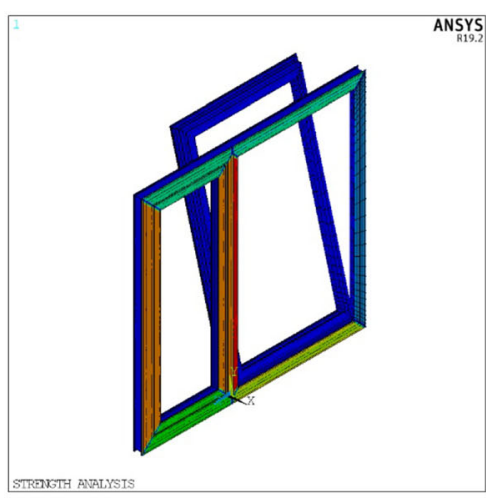

(a) Window temperature

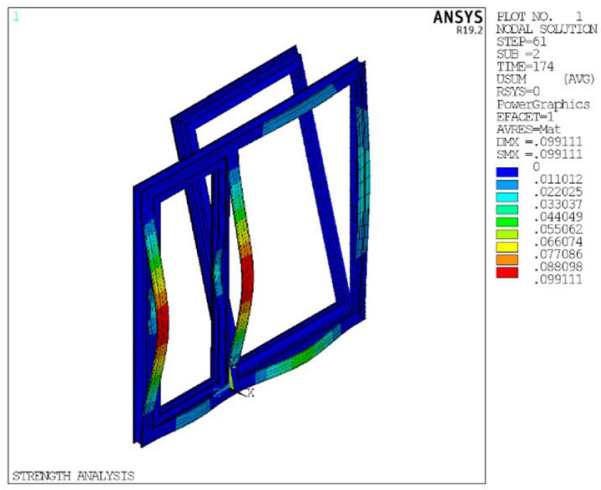

(b) Window deformation

Figure 20. Frame temperature (a) and deformation (b) before failure of outer frame at $174 \mathrm{~s}$ of fire exposure for the in-tilt window configuration.

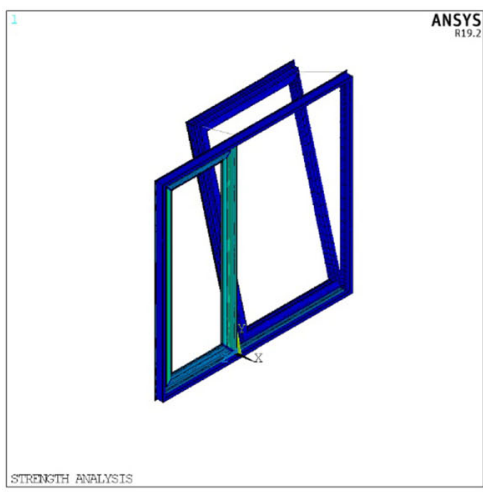

(a) Temperature at external side

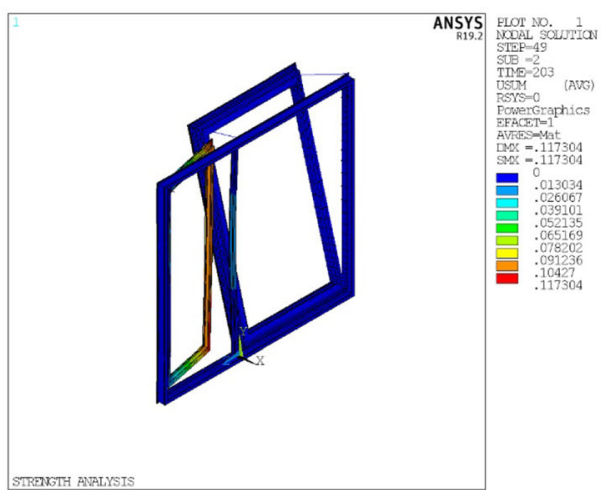

(b) Window deformation

Figure 21. Frame temperature (a) and deformation (b) before failure of outer frame at 203 s of fire exposure for the tilted-in window configuration.

moment is not too high (about $270{ }^{\circ} \mathrm{C}$ ) and the aluminium will still resist the loads. In that case, the complete collapse of the window occurs at the melting point of the window frame, at about $4 \mathrm{~min}$. 


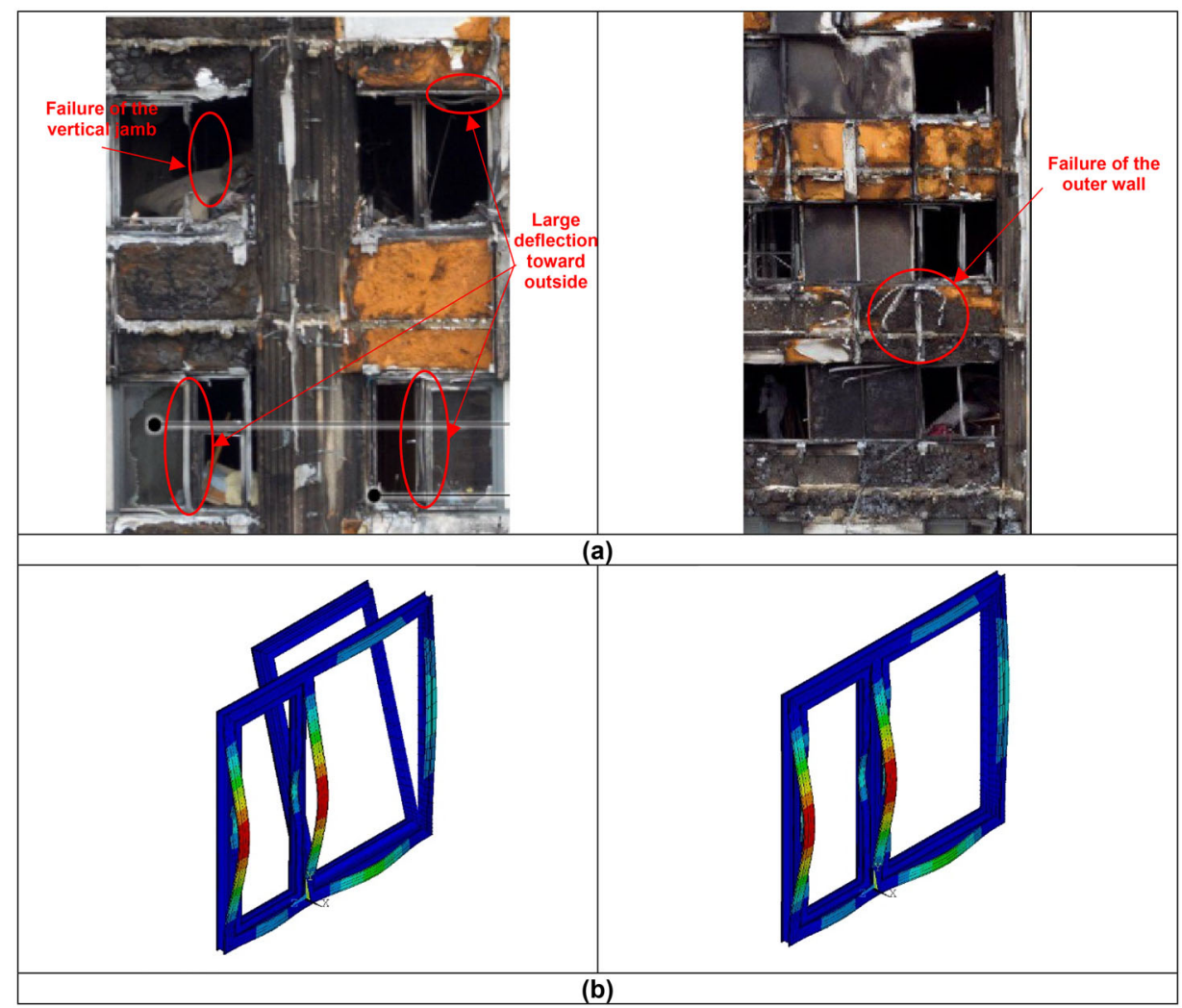

Figure 22. (a) Failure of window frame with outward fallout of the external frame of windows, L. Bisby's expert report [30], Fig. 109 and 110 , p. 166, (b) oułward failure of window frame evaluated numerically for two opening configurations.

\section{Comparison Between the Numerical Results and the Observations of Window Failure During The Disaster}

The numerically modelled thermomechanical deformation of the window frames are compared with observations after the real fire in Fig. 22. Partial failures of windows are visible, with the external part of the frame detached from the window and falling outward. Large deflections of vertical or horizontal Parts of the frame occurred during the Grenfell Tower disaster. The numerical model yields the same behaviour, whatever the opening configuration of the window.

The results of the thermomechanical analysis for the window failure times are collated in Table 4. The first failure of the window frame is observed after $3 \mathrm{~min}$ of fire exposure and the frame falls toward the exterior. The complete failure of window occurs at about $4 \mathrm{~min}$. The last failure may be at about $5 \mathrm{~min}$ as the heating is delayed about $1 \mathrm{~min}$ for some of the external profiles. However, even if 


\section{Table 4}

Summary of the window failure analysis

\begin{tabular}{lccc}
\hline & & \multicolumn{2}{c}{ Total failure } \\
\cline { 3 - 4 } $\begin{array}{l}\text { Window } \\
\text { position }\end{array}$ & $\begin{array}{c}\text { Partial failure of exter- } \\
\text { nal frame profile }\end{array}$ & $\begin{array}{l}\text { Failure due to the dynamic force applied } \\
\text { from window's connections }\end{array}$ & $\begin{array}{c}\text { Failure due } \\
\text { material warm- } \\
\text { ing }\end{array}$ \\
\hline Closed & 3 min (toward outside) & $3 / 4$ min (toward outside) & $\begin{array}{l}4 / 5 \text { min (toward } \\
\text { inside) }\end{array}$ \\
Tilted-in & 3 min (toward outside) & $3 / 4$ min (external profile toward outside) & $\begin{array}{l}3.5 / 5 \text { min (to- } \\
\text { ward inside) }\end{array}$ \\
\hline
\end{tabular}

a part of the window frame stays in place, the glass breakage is almost certain at this moment, due to the large deformation of the frame leading to mechanical stress, or because it will fall out when the frame no longer holds it in place.

\section{Conclusion}

The thermomechanical behaviour of the refurbished windows of the Grenfell tower was investigated numerically. This analysis was based on a previous study of the fire development from the initial apartment to those above it. The thermal loads and heat transfer coefficients at windows assessed numerically in [34] are used as boundary conditions in order to perform a thermal analysis of the window frame.

The thermal, and then thermomechanical behaviour of a typical window is addressed for initially closed and initially tilted-in casement configurations to analyse whether the window collapses inwards or outwards. Direct thermal analysis is not relevant for the materials subject to failure or melting during the heating. Therefore, this analysis considers the failure of the external profile of the window. Thermal and thermomechanical results show that the failure of the window is in accordance with observations of the real fire.

For both window casement opening configurations, the thermal melting of the frame is expected between 3 and $4 \mathrm{~min}$ of exposure. The polyamide thermal breaks close to the exposed side of the window frame melted between 2 and 4.5 min depending on their position. The failure of the external profile of the frame is then expected between 3 and 4 min of exposure. The thermomechanical analysis showed a strong deformation of the frame after $3 \mathrm{~min}$ of exposure. The outer profile of the window is expected to be partially or totally damaged during this time.

In the case of a closed casement, the outer face detached from the rest of the window and failed outwards after about $3 \mathrm{~min}$ of fire exposure. At this time, the dynamic force due to the weight of the outer profile of the frame may cause out- 
ward collapse if the assemblies between the frame and the supporting structure remain strong. If the overall collapse of the window does not occur at the same time as the collapse of its outer profile, the inner profile of the window fails towards the interior at $4 \mathrm{~min}$. In the case of an tilted-in casement, the outer profile detached from the rest of the window and failed outwards after about $3 \mathrm{~min}$ of fire exposure. However, it is unlikely that the failure of the outer profile of the frame generated a complete outward collapse of the window. The distortion of the remaining inner profile of the window and the casement promoted an inward failure. The opening of the small side-hung casement due to the action of fire is also observed. Even if a part of the window frame stays in place, the glass breakage is almost certain at this moment, due to the large deformation of the frame leading to mechanical stress, or because it will fall out when the frame no longer holds it in place.

The aim of the current study was to carry out a deeper investigation into the thermal and thermo-mechanical behaviour of the Grenfell Tower windows during the disaster, with an evaluation of the thermal criteria for window failure. The relevance of the hypothesis used in the previous numerical studies for the reconstruction of the Grenfell fire $[34,37]$ was then shown. The influence of the initial window casement position was also investigated to enhance the understanding of the several failure modes (inward or outward fallout) of the window frames observed after the fire event. The relation between the initial position of the window casement during the disaster (close, open, tilted-in) and its fallout mode was investigated. Partial failure of windows is visible, with the external profile of the frame detached from the window and falling outwards. The same behaviour was visible from the numerical model, whatever the opening configuration of the window casement. The thermal and thermomechanical modelling results showed consistency between the failure time of the windows and the failure time criterion of 4 min used in the fire development model.

Although several factors, happening simultaneously or as consequence of each other, were involved in the Grenfell Tower fire, the lack of fire performance of the windows is one of the main causes of massive fire re-entry from the external façade to the apartments, even during the initial vertical fire spread over the façade. Different casement opening configurations do not impact the time to failure of the frame. Thus, whatever the initial casement opening configuration, the severe external fire loads would have led to the deformation of the frame followed by its fallout within a few minutes, allowing flames and toxic smoke to enter the different apartments [50-53].

As well as the investigation of the Grenfell Tower windows, this paper presents two different ways of modelling convective effects in cavities, using the ANSYS finite element model. The comparison between the results for both methods are in a good agreement. The Pearson correlation coefficient between two models is of 0.986. Simulations also show that thermal heating through the cavities, during the computation interval, is not strongly dependant on the film coefficient, as the variation of temperature in the cavities is quite low. 


\section{Open Access}

This article is licensed under a Creative Commons Attribution 4.0 International License, which permits use, sharing, adaptation, distribution and reproduction in any medium or format, as long as you give appropriate credit to the original author(s) and the source, provide a link to the Creative Commons licence, and indicate if changes were made.

The images or other third party material in this article are included in the articleã s Creative Commons licence, unless indicated otherwise in a credit line to the material. If material is not included in the articleã s Creative Commons licence and your intended use is not permitted by statutory regulation or exceeds the permitted use, you will need to obtain permission directly from the copyright holder.

To view a copy of this licence, visit http://creativecommons.org/licenses/by/4.0/.

\section{References}

1. Karlsson B, Quintiere J (1999) Enclosure fire dynamics. CRC Press, Cambridge

2. Peatross MJ, Beyler CL (1997) Ventilation effects on compartment fire characterization. In: Fire safety science-proceedings of the fifth international symposium, pp 403-414

3. Oleszkiewicz I (1989) Heat transfer from a window fire plume to a building façade, National Research Council of Canada

4. Kim WK (1990) Exterior fire propagation in a high rise building, Worcester Polytechnic Institute, Thesis

5. Lost Prevention Council (1999) Fire spread in Multi-Story Buildings with Glazed Curtain Wall Facades, England

6. Keski-Rahkonen O (1988) Breaking of window glass close to fire. Fire Mater 12:61-69

7. Emmons HW (1988) Window glass breakage by Fire. Home Fire Project Technical Report No. 77, Harvard University

8. Pagni PJ, Joshi AA (1991) Glass breaking in fires. Fire Saf Sci 3:791-802

9. Shields TJ, Silcock GW, Flood MF (2005) Behaviour of double glazing in corner fires. Fire Technol 41(2005):37-65

10. Skelly MJ, Roby RJ, Beyler CL (1991) An experimental investigation of glass breakage in compartment fires. J Fire Prot Eng 3(1):25-34

11. Shields TJ, Silcock GW, Flood MF (2001) Performance of single glazing assembly exposed to corner fires of increasing severity. Fire Mater 25(4):123-152

12. Hietaniemi J (2005) Probabilistic simulation of glass fracture and fallout in fire. VTT Building and Transport, Espoo

13. Klassen MS, Sutula JA, Holton MM, Roby RJ, Izbicki T (2006) Transmission through and breakage of multi-pane glazing due to radiant exposure. Fire Technol 42:79-107

14. Mowrer FW (1997) Window breakage induced by exterior fires. In: 2nd international conference on fire research and engineering (ICFRE2), Gaithersburg, MD

15. Projet National ISI - Comportement au feu des vitrages non résistants au feu, A14G14-rapport d'action, 30 Oct 2010. www.pn-isi.fr

16. Babrauskas V (2010) Glass breakage in fires. Fire Science and Technology Inc, 2010

17. Shields TJ, Silcock GW, Flood MF (1998) The behavior of double glazing in an enclosure fire. J Appl Fire Sci 7(3):267-286 
18. Cuzzillo BR, Pagni PJ (1998) Thermal breakage of double-pane glazing by fire. J Fire Prot Eng 9(1):1-11

19. Pagni PJ, Joshi AA (1993) Fire-induced thermal fields in window glass I. Theory Fire Saf J 22(1994):25-43

20. Pagni PJ, Joshi AA (1993) Fire-induced thermal fields in window glass II. Exp Fire Saf J 22(1994):46-45

21. Pagni PJ (1989) Fire physics; promises, problems and progress. Fire safety science. In: Proceedings of 2nd international symposium, pp 49-66

22. Pagni PJ, Joshi AA (1991) Users' guide to BREAK1, The Berkeley Algorithm for Breaking Window Glass in a Compartment Fire. NIST-GCR-91-596

23. Parry R (2003) Implementation of a glass fracture module for the BRANZfire compartment fire zone modelling software. University of Canterburry, Master thesis 2003

24. Dembele S, Rosario RAF, Wen JX, Wang QS, Warren PD (2010) Thermal and stress analysis of glazing in fires and glass fracture modelling with a probabilistic approach. Int J Comput Methodol 58(6):419-439

25. Dembele S, Rosario RAF, Wen JX (2012) Thermal breakage of window glass in room fires conditions analysis of some important parameters. Build Environ 54(2012):61-70

26. Kang K (2009) Assessment of a model development for window glass breakage due to fire exposure in a field model. Fire Saf J 44(2009):415-424

27. Qing-song W, Yi Z, Jin-hua S, Wen J, Dembele S (2011) Temperature and thermal stress simulation of window glass exposed to fire. Proc Eng 11(2011):452-460

28. Huizinga RA (2012) Influence of the performance of triple and double glazing on the fire development in a dwelling, Master thesis, Eindhoven University of Technology

29. Moore-Bick M (2019) Grenfell tower inquiry: phase 1 report - Report of the public inquiry into the fire at Grenfell tower on 14 june 2017; The Grenfell Tower Inquiry (October, 30th 2019), Phase 1 reports, www.grenfelltowerinquiry.org.uk/

30. Bisby L., Grenfell Tower Inquiry report. Phase 1: Expert report. 2nd April 2018. http s://www.grenfelltowerinquiry.org.uk/evidence/professor-luke-bisbys-expert-report

31. Lane B (2018) Grenfell Tower-fire safety investigation. 12th April 2018. https://www.g renfelltowerinquiry.org.uk/evidence/dr-barbara-lanes-expert-report

32. Torero J (2018) Grenfell Tower: phase 1 report. GFT 1710-OC-001-DR-01-May 23rd 2018. https://www.grenfelltowerinquiry.org.uk/evidence/professor-jose-1-toreros-expert-r eport

33. Guillaume E, Dréan V, Girardin B, Benameur F, Fateh T (2019) Reconstruction of Grenfell Tower fire. Part 1: Lessons from observations and determination of work hypotheses. Fire Mater 44(1). https://doi.org/10.1002/fam.2766

34. Guillaume E, Dréan V, Girardin B, Koohkan M, Fateh T (2019) Reconstruction of Grenfell Tower Fire. Part 2: A numerical investigation of the fire propagation and behaviour from the initial apartment to the Façade. Fire Mater 44(1). https://doi.org/10 $.1002 /$ fam. 2765

35. Fire dynamics simulator FDS, https://www.nist.gov/

36. Guillaume E, Dréan V, Girardin B, Benameur F, Koohkan M, Fateh T (2019) Reconstruction of Grenfell Tower Fire. Part 3-Numerical simulation of the Grenfell Tower disaster: contribution to the understanding of the fire propagation and behaviour during the vertical fire spread. Fire Mater 44(1). https://doi.org/10.1002/fam.2763

37. ANSYS 17.2, August 2016, https://www.ansys.com/

38. MetalTechnology system 5-20 datasheet. https://www.metaltechnology.com/products/ system-5-20/. Accessed June 2019

39. Kensington and Chelsea TMO, Reduced window opening inware opening leafs, Grenfell tower regeneration project, Drawing NO. 1279 SK112 01 
40. Weather in London, England, United Kingdom, www.timeanddate.com/weather/uk/lon don

41. Carriěre JF, Sekiguchi H (1976) Thermal properties of amino acid type polyamides. Chem Zvesti 30(3):281-291

42. Eurocode 1 (EN 1991), Part 1-2: design of aluminium structures - structural fire design

43. BS EN 755 Part 2 (April 2016), Aluminium and aluminium alloys - extruded rod/bar, tube and profiles-Part 2: mechanical properties-aluminium and aluminium alloys - mechanical characteristics

44. Mróz A (2014) The viscoplastic effect in the heat-treated, thin-walled AL-6060 alloy profiles subjected to compressive axial impact. Mech Mech Eng 18(1):53-71

45. Okada T, Ishige R, Ando S (2016) Analysis of thermal radiation properties of polyimide and polymeric materials based on ATR-IR spectroscopy. J Photopolym Sci Technol 29(2):251-254

46. Raman R, Thakur A (1982) Thermal emissivity of materials. Appl Energy 12(3):205220

47. Eurocode 1( EN 1991), Part 1-2: actions on structures - actions on structures exposed to fire

48. Tan YL, Huang CH, Guo ZX, Yu J (2018) Morphology and mechanical properties of polyamide 6/polystyrene blends prepared by diffusion and subsequent polymerization of styrene in polyamide 6 pellets. Material 11:776

49. Eurocode 1( EN 1991), Part 1-4: actions on structures - wind actions

50. Eurocode 1 (EN 1991), Part 1-1: design of aluminium structures - general structural rules

51. EN 1992-1-2, October 2005 "Eurocode 2: Design of concrete structures-Part 1-2: General rules-Structural fire design."

52. Eurocode 0 (EN 1990), Basis of structural design

53. Eurocode 1 (EN 1991), Part 1-1: actions on structures-densities, self-weight, imposed loads for buildings

Publisher's Note Springer Nature remains neutral with regard to jurisdictional claims in published maps and institutional affiliations. 